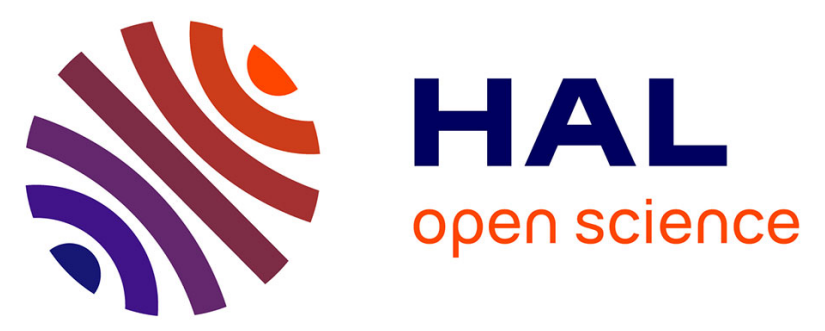

\title{
Electronic Communication within Flexible Bisdithiolene Ligands Bridging Molybdenum Centers
}

\author{
Antoine Vacher, Yann Le Gal, Thierry Roisnel, Vincent Dorcet, Thomas
}

Devic, F Barriere, Dominique Lorcy

\section{- To cite this version:}

Antoine Vacher, Yann Le Gal, Thierry Roisnel, Vincent Dorcet, Thomas Devic, et al.. Electronic Communication within Flexible Bisdithiolene Ligands Bridging Molybdenum Centers. Organometallics, 2019, 38 (22), pp.4399-4408. 10.1021/acs.organomet.9b00485 . hal-02438532

HAL Id: hal-02438532

https://hal-univ-rennes1.archives-ouvertes.fr/hal-02438532

Submitted on 21 Feb 2020

HAL is a multi-disciplinary open access archive for the deposit and dissemination of scientific research documents, whether they are published or not. The documents may come from teaching and research institutions in France or abroad, or from public or private research centers.
L'archive ouverte pluridisciplinaire HAL, est destinée au dépôt et à la diffusion de documents scientifiques de niveau recherche, publiés ou non, émanant des établissements d'enseignement et de recherche français ou étrangers, des laboratoires publics ou privés. 


\title{
Electronic communication within flexible bisdithiolene ligands bridging molybdenum centers.
}

Antoine Vacher, ${ }^{\mathrm{a}}$ Yann Le Gal, ${ }^{\mathrm{a}}$ Thierry Roisnel, ${ }^{\mathrm{a}}$ Vincent Dorcet, ${ }^{\mathrm{a}}$ Thomas Devic, ${ }^{\mathrm{b}}$ Frédéric Barrière, ${ }^{\mathrm{a}}$ Dominique Lorcy ${ }^{\mathrm{a}^{*}}$

${ }^{a}$ Univ Rennes, CNRS, ISCR (Institut des Sciences Chimiques de Rennes) - UMR 6226, F35000 Rennes, France.Tel: 3322323 6273; E-mail: Dominique.lorcy@univ-

rennes1.fr,orcid.org/0000-0002-7698-8452

${ }^{b}$ Institut des Matériaux Jean Rouxel (IMN), Université de Nantes, UMR CNRS 6502, 2 rue de la Houssinière, BP 32229, 44322 Nantes Cedex 3, France

\begin{abstract}
Bimetallic molybdenum dithiolene complexes involving two flexible ditopic conjugated linkers have been synthetized and characterized by electrochemistry, spectro-electrochemistry and single crystal X-ray diffraction. The

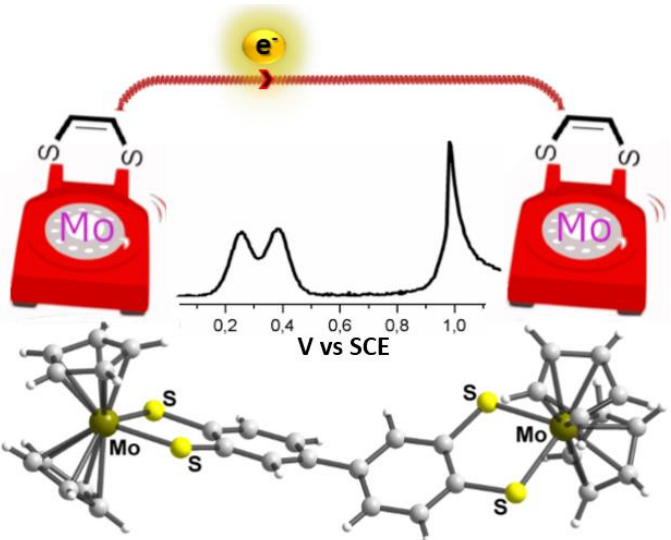
electrochemical investigations evidence that the two metallic bisdithiolene moieties are electronically coupled in the monocationic state. DFT and TD-DFT calculations further suggest that the intervalence charge transfer within both monocations is essentially localized on the ligand and can be described as an intra-ligand charge transfer (ILCT).
\end{abstract}

\section{Introduction}

Electronic communication in bimetallic complexes have attracted a lot of attention both from a theoretical point of view and for potential applications in molecular electronics or as model to 
mimic biological electron transfer. ${ }^{1,2}$ These systems are also appealing models to understand electronic conduction within extended networks. Bisdithiolene ligands are interesting as conjugated bridging organic moieties between redox active metal centers as they may potentially mediate or even participate into metal/metal electronic coupling. Indeed dithiolene ligands are considered as archetypical non-innocent ligands, and, thanks to electron delocalization over the metallacycle generated by the mixing of the metal and ligand orbitals, metalladithiolene complexes present multiple and successive addressable redox states. ${ }^{3,4}$ Among the few bisdithiolene ligands reported to date, some are rigid and present both dithiolene units in the same plane such as tetrathiooxalate $(\mathrm{tto})^{5}$ or $1,2,4,5$-benzenetetrathiolate $(\mathrm{btt})^{6}$ (Chart 1). Both ligands have led to various bi- or poly-metallic complexes where strong electronic interactions between the redox units have been evidenced.5,6,7 Another planar bisdithiolene ligand is tetrathiafulvalene-4,4',5,5'-tetrathiolate (TTFtt, Chart 1). Different bimetallic complexes have been reported but no electronic interaction has been observed between the redox-active metallic centers across the TTF backbone. ${ }^{8}$ The second class of bisdithiolene ligands consists of two dithiolene moieties that are not constrained to coplanarity, such as 1,2,3,4-butadiene tetrathiolate (bdtt), ${ }^{9} 4,4^{\prime}$-di(benzenedithiolate) (dbdt, L1) ${ }^{10}$ or benzene-1,4-di(ethylenedithiolate) (bdedt, L2) (Chart 1). It is worth mentioning that for the two latter bisdithiolene ligands, no bimetallic complexes have been reported so far, while only one example of a tetranuclear complex with a close ligand $(\mathbf{M e} 3 \mathbf{S i})_{2} \mathbf{L} 2$ is described (see Chart 2). ${ }^{11}$ Considering the scarcity of such complexes, we decided to investigate how these flexible ligands, namely dbdt (L1) and bdedt (L2), can act as bridging moieties between two metallic centers. 
Chart 1<smiles>[S-]C([S-])=C([S-])[S-]</smiles><smiles>[S-]c1cc(S)c(S)cc1S</smiles><smiles>S=C1SC(=C2SC([S-])=C([S-])S2)SC1=S</smiles><smiles>[S-]C=C([S-])C(S)=C[S-]</smiles><smiles>[S-]C=C([S-])c1ccc(C(S)=C[S-])cc1</smiles>

In order to probe the possible electronic communication along or within these organic bridges including the two (metal)dithiolene moieties, we focused our attention on their bis(cyclopentadienyl) dithiolene molybdenum complexes, $\mathrm{Cp}_{2} \mathrm{Mo}$ (dithiolene). Indeed, these $\mathrm{d}^{2}$ complexes belong to an interesting family of redox active derivatives that can be easily oxidized reversibly into the cation radical and the dicationic species. ${ }^{12,13,14,15,16}$ Herein, we report the synthesis of two bimetallic complexes, namely $\left(\mathrm{Cp}_{2} \mathrm{Mo}\right)_{2}(\mathrm{dbdt})$ and $\left(\mathrm{Cp}_{2} \mathrm{Mo}\right)_{2}$ (bdedt) $(\mathbf{M o} \mathbf{L} \mathbf{L}$ and $\mathbf{M o}_{2} \mathbf{L} 2$ respectively, Chart 2). Electrochemical and spectroelectrochemical investigations, supported by DFT calculations, evidence that, although potentially flexible, these ligands can give rise to strong electronic interaction between the metalladithiolene units.

\section{Chart 2}
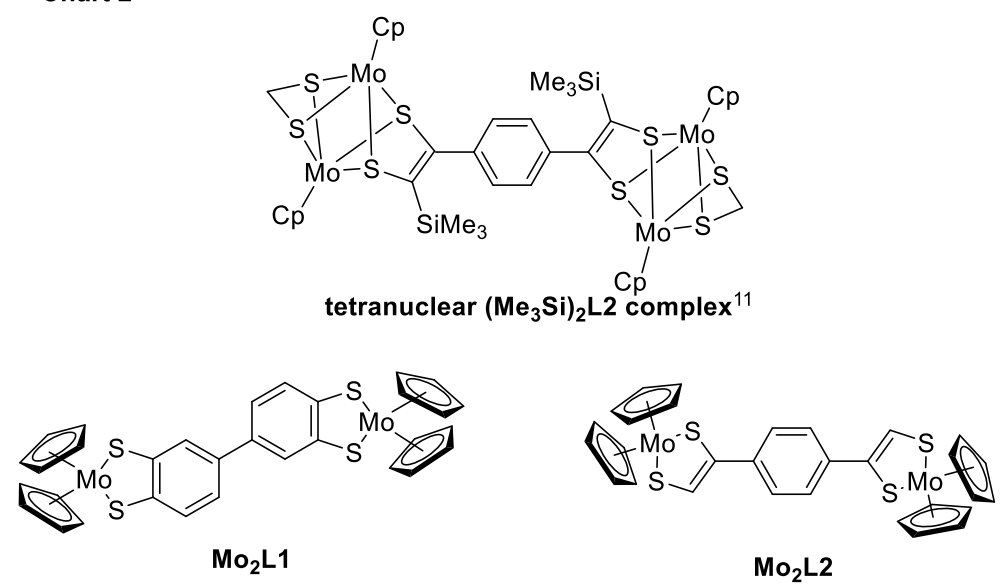


\section{Results and discussion}

Synthesis of the proligands. Various protecting groups of the dithiolene ligand have been proposed to prepare dithiolene complexes: either organic protecting groups such as cyanoethyl and carbonyl groups ${ }^{17}$ or inorganic ones such as dialkyltin ${ }^{18}$ and zinc complexes. ${ }^{19}$ Deprotection requires the use of a strong base (sodium methanolate) in the case of an organic protecting group. On the other hand, inorganic protecting group are readily displaced by metal dichloride derivatives by ligand exchange so that no specific deprotecting step is needed. Such a transmetallation realized with dialkyltin protected molecule is known to be cleaner than with zinc and to generate highly soluble by-products that are easier to work up. ${ }^{18}$ Therefore, we decided to prepare the target bisdithiolene protected ligands by a dialkyltin group $\mathbf{S n} 2 \mathbf{L} \mathbf{1}$ and Sn2L2 as shown in Chart 3.
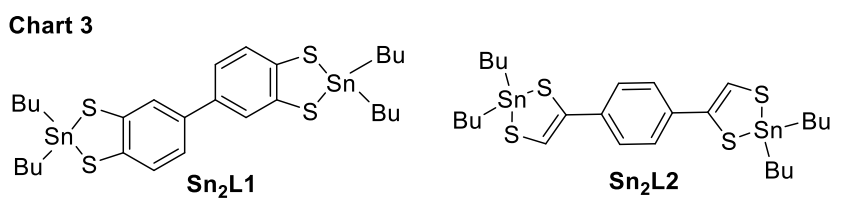

The synthesis of ligand $\mathbf{L} \mathbf{1}$ protected by dimethyltin groups has been reported previously. ${ }^{10}$ However, in order to increase the solubility of this proligand, dibutyltin derivative $\mathbf{S n} \mathbf{L} \mathbf{L} \mathbf{1}$ was prepared instead. For the second bridging ligand, L2, the dithiole-2-one protected ligand was first prepared, and further converted into the dibutyltin protected $\mathbf{S n}_{2} \mathbf{L} 2$ (Scheme 1). For that purpose, 1,4-bis(bromoacetyl)benzene 1 was reacted with potassium xanthate salt. ${ }^{20}$ The ring closure was performed in acidic medium to afford the 4,4'-(1,4-phenylene)bis-1,3-dithiol-2one 2. In order to generate the dibutyltin protected dithiolene ligand, we used $\mathbf{2}$ as starting material. The dithiolene ligand was first deprotected through the use of sodium methanolate and then reacted with dichlorodibutyltin to afford the protected dithiolene ligand $\mathbf{S n}_{2} \mathbf{L} 2$. Recrystallization of those two proligands afforded crystals suitable for X-ray diffraction studies. The molecular structure of both proligands $\mathbf{2}$ and one of the two crystallographically 
independent molecule $\mathbf{S n}_{2} \mathbf{L} 2$ (molecule A) are presented in Figure 1. Selected bond lengths and angles are collected in Table 1. As expected, both proligands $\mathbf{2}$ and $\mathbf{S} \mathbf{n}_{2} \mathbf{L} \mathbf{2}$ are not planar (Figure 1): in 2 , the dihedral angle between the dithiol-2-one rings and the phenyl ring is $22.8(2)^{\circ}$, while in $\mathbf{S n}_{2} \mathbf{L} 2$, the angle between the metalladithiolene moieties and the phenyl rings is $35.4(2)^{\circ}$ for molecule $\mathrm{A}$ and $33.9(6)^{\circ}$ for molecule $\mathrm{B}$. The dithiole dibutyltin heterocyclic rings are themselves distorted along the $\mathrm{S} \cdots \mathrm{S}$ hinge with an angle of $20.2(2)^{\circ}$ in molecule A and $10.7(9)^{\circ}$ in molecule B.
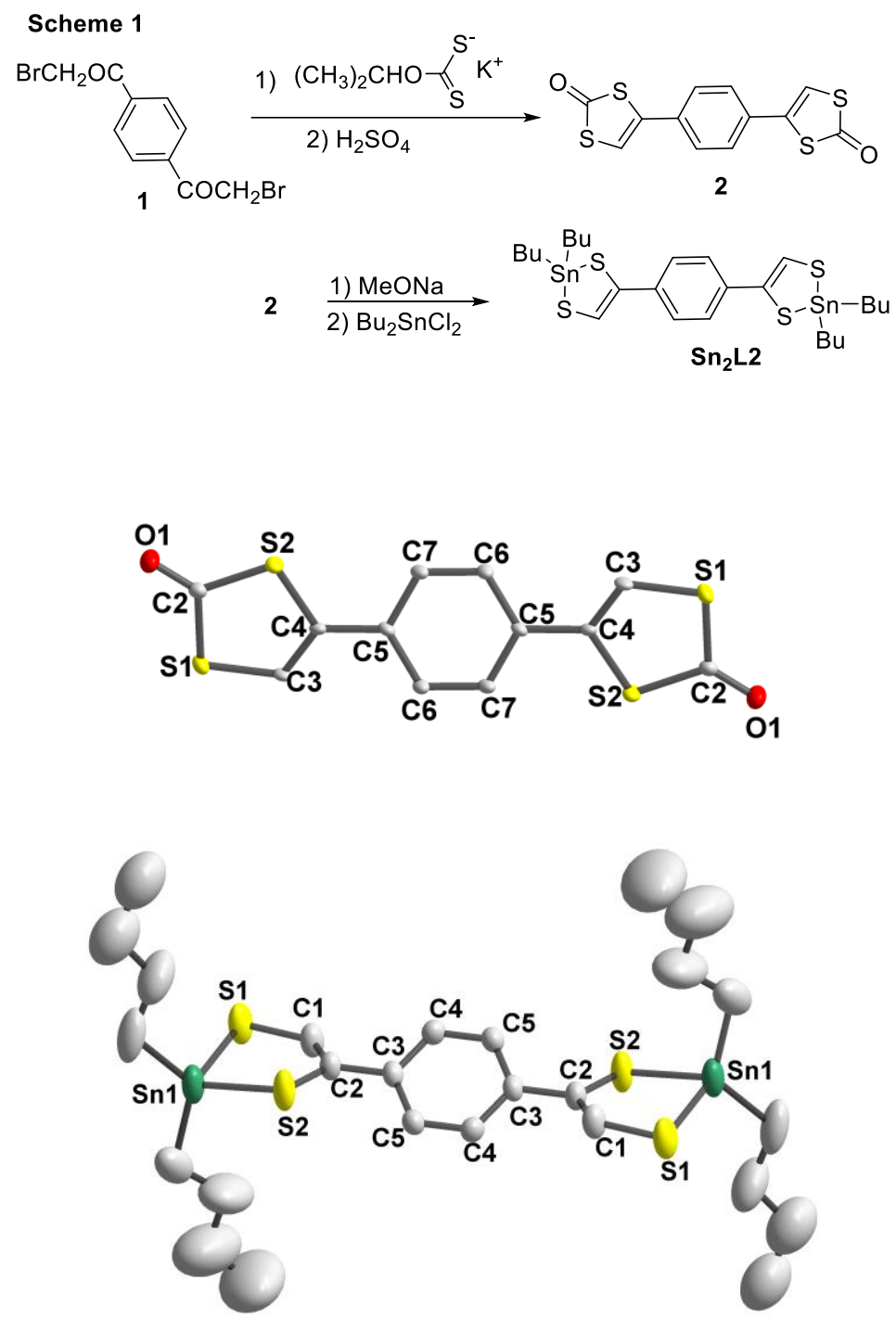

Figure 1 Molecular structures of proligands 2 (top) and $\mathbf{S n}_{2} \mathbf{L} 2$ (one of two crystallographically independent molecules, molecule A, bottom). Thermal ellipsoids are drawn at 50\% probability level. $\mathrm{H}$ atoms have been omitted for clarity. 
Syntheses of the complexes. The chemical approach followed for the synthesis of the target molecules is described in Scheme 2. The reactivity of the protected bis(phenyldithiolene) ligand Sn $2 \mathbf{L 1}$ towards $\mathrm{Cp}_{2} \mathrm{MoCl}_{2}$ was first studied. By simply heating a solution of this ligand with an excess of $\mathrm{Cp}_{2} \mathrm{MoCl}_{2}$ in $\mathrm{CHCl}_{3} / \mathrm{THF}$ (50/50) the desired complex $\mathbf{M o} \mathbf{L}_{2} \mathbf{L} \mathbf{1}$ was successfully formed in $35 \%$ yield together with the mono molybdenum complex SnL1Mo in $15 \%$ yield. Mo2L1 and SnL1Mo were easily separated by column chromatography. The reaction of the dibutyltin protected proligand $\mathbf{S n} 2 \mathbf{L} 2$ with $\mathrm{Cp}_{2} \mathrm{MoCl}_{2}$ was also attempted. However, whatever the experimental conditions tested it was impossible to isolate the desired complex. Nevertheless, addition of NaOMe to the proligand 4,4'-(1,4-phenylene)bis-1,3-dithiol-2-one 2 followed by the addition of an excess of $\mathrm{Cp}_{2} \mathrm{MoCl}_{2}$ gave $\mathbf{M o} \mathbf{L}_{2} \mathbf{L} 2$ in $85 \%$ yield (Scheme 2).

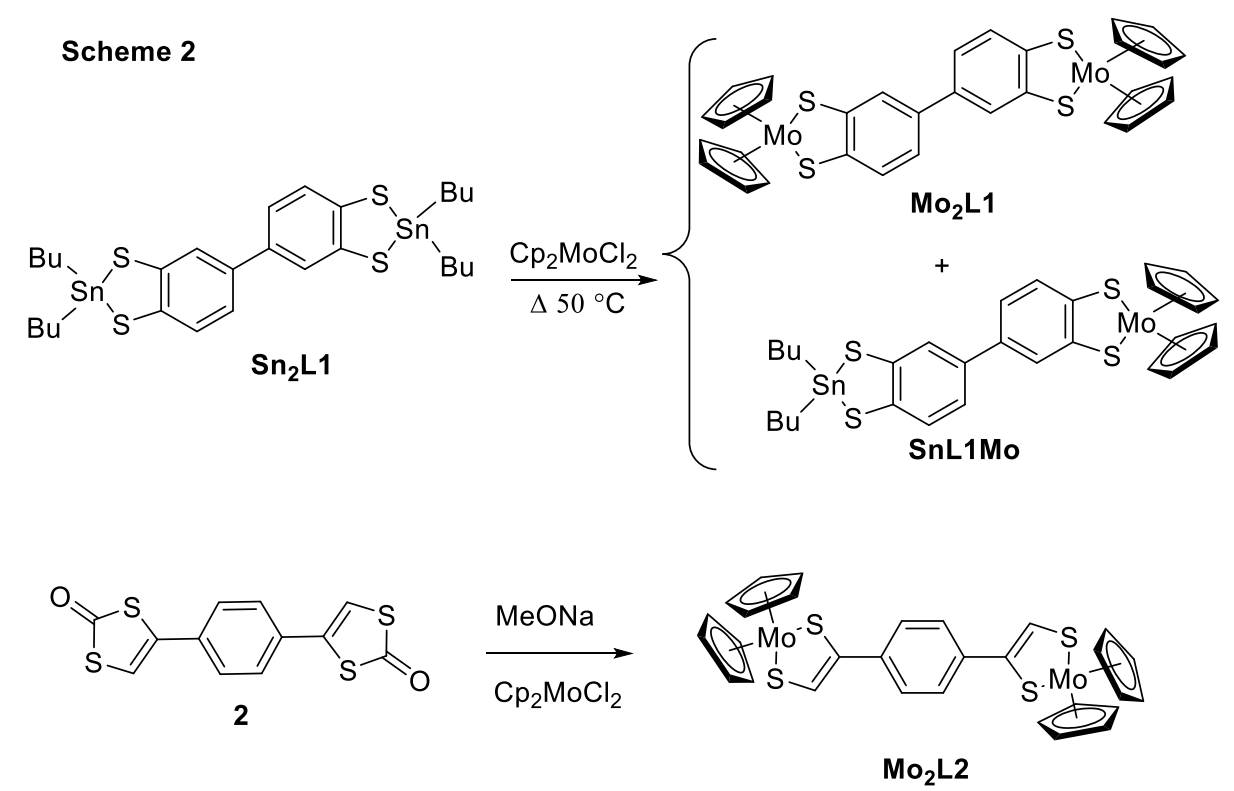

Crystals suitable for X-ray structure analysis were obtained for both $\mathbf{M o z}_{2} \mathbf{L} 1$ and $\mathbf{M o z}_{2} \mathbf{L} 2$. Mo2L1 was isolated as a dichloromethane solvate and $\mathbf{M o}_{2} \mathbf{L 2}$ as a chloroform solvate formulated respectively as $\mathbf{M o}_{2} \mathbf{L} 1 \cdot 0.5 \mathrm{CH}_{2} \mathrm{Cl}_{2}$ and $\mathbf{M o}_{2} \mathbf{L} \mathbf{2} \cdot 0.5 \mathrm{CHCl}_{3}$. These compounds 
crystallize in the monoclinic system, space group $P 2_{1} / n$ for $\mathbf{M o}_{2} \mathbf{L} \mathbf{1} .0 .5 \mathrm{CH}_{2} \mathrm{Cl}_{2}$ and $P{ }_{1} / c$ for $\mathbf{M o}_{2} \mathbf{L} 2.0 .5 \mathrm{CHCl}_{3}$. The molecular structures of both complexes are presented in Figure 2. Selected bond lengths and angles are listed in Table 1 together with those of the reference compounds $\mathrm{Cp}_{2} \mathrm{Mo}(\mathrm{bdt})$ and $\mathrm{Cp}_{2} \mathrm{Mo}(\mathrm{sdt})$ (bdt: benzenedithiolate and sdt: styrene-1,2dithiolate).

Table 1. Bond lengths $(\AA)$ and $\theta$ angles $\left(^{\circ}\right)$ in the metallacycle for complexes $\operatorname{Sn}_{2} \mathbf{L} 2, \mathbf{M o}_{2} \mathbf{L 1}$, $\mathbf{M o}_{2} \mathbf{L} 2, \mathrm{Cp}_{2} \mathrm{Mo}(\mathrm{sdt})$ and $\mathrm{Cp}_{2} \mathrm{Mo}(\mathrm{bdt})$

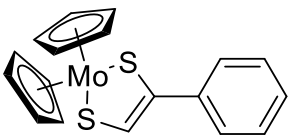

$C p_{2} M o(s d t)$

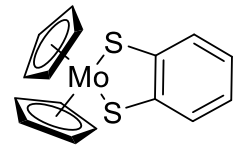

$\mathrm{Cp}_{2} \mathrm{Mo}(\mathrm{bdt})$

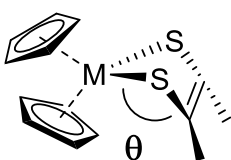

$\theta$

\begin{tabular}{|c|c|c|c|c|}
\hline & M-S & C-S & $\mathrm{C}=\mathrm{C}$ & $\theta$ \\
\hline \multirow{6}{*}{$\mathrm{Sn}_{2} \mathbf{L} 2$} & Molecule A & & \multirow[b]{3}{*}{$1.344(8)$} & \multirow[b]{3}{*}{$20.2(2)$} \\
\hline & $\mathrm{Sn}_{1}-\mathrm{S}_{1} 2.419(2)$ & $\mathrm{S}_{1}-\mathrm{C}_{1} 1.753(6)$ & & \\
\hline & $\mathrm{Sn}_{1}-\mathrm{S}_{2} 2.436(1)$ & $S_{2}-C_{2} 1.765(5)$ & & \\
\hline & \multicolumn{4}{|l|}{ Molecule B } \\
\hline & $\mathrm{Sn}_{2}-\mathrm{S}_{21} 2.428(2)$ & $\mathrm{S}_{21}-\mathrm{C}_{21} 1.756(9)$ & \multirow{2}{*}{$1.334(9)$} & \multirow[b]{2}{*}{$10.7(9)$} \\
\hline & $\mathrm{Sn}_{2}-\mathrm{S}_{22} 2.427(2)$ & $\mathrm{S}_{22}-\mathrm{C}_{22} 1.773(5)$ & & \\
\hline \multirow[t]{4}{*}{$\mathrm{Mo}_{2} \mathrm{L1}$} & $\mathrm{Mo}_{1}-\mathrm{S}_{1} 2.437(1)$ & $\mathrm{S}_{1}-\mathrm{C}_{11} 1.763(4)$ & \multirow[t]{2}{*}{$1.406(6)$} & \multirow[t]{2}{*}{$2.6(2)\left(\mathrm{Mo}_{1}\right)$} \\
\hline & $\mathrm{Mo}_{1}-\mathrm{S}_{2} 2.446(1)$ & $\mathrm{S}_{2}-\mathrm{C}_{12} 1.764(4)$ & & \\
\hline & $\mathrm{Mo}_{2}-\mathrm{S}_{3} 2.434(1)$ & $\mathrm{S}_{3}-\mathrm{C}_{31} 1.755(4)$ & \multirow[t]{2}{*}{$1.402(6)$} & \multirow[t]{2}{*}{ 5.1(1) $\left(\mathrm{Mo}_{2}\right)$} \\
\hline & $\mathrm{Mo}_{2}-\mathrm{S}_{4} 2.441(1)$ & $\mathrm{S}_{4}-\mathrm{C}_{32} 1.767(4)$ & & \\
\hline $\mathrm{Cp}_{2} \mathrm{Mo}(\mathrm{bdt})^{21}$ & Mo-S 2.437(3) & $1.78(1)$ & $1.35(3)$ & 9 \\
\hline \multirow{4}{*}{$\mathrm{Mo}_{2} \mathrm{~L} 2$} & $\mathrm{Mo}_{1}-\mathrm{S}_{1} 2.438(2)$ & $\mathrm{S}_{1}-\mathrm{C}_{11} 1.766(10)$ & \multirow[t]{2}{*}{$1.333(14)$} & \multirow[t]{2}{*}{$4.2(3)\left(\mathrm{Mo}_{1}\right)$} \\
\hline & $\mathrm{Mo}_{1}-\mathrm{S}_{2} 2.438(3)$ & $\mathrm{S}_{2}-\mathrm{C}_{12} 1.735(10)$ & & \\
\hline & $\mathrm{Mo}_{2}-\mathrm{S}_{11} 2.445(2)$ & $\mathrm{S}_{11}-\mathrm{C}_{32} 1.769(11)$ & \multirow[t]{2}{*}{$1.345(14)$} & \multirow[t]{2}{*}{$3.1(3)\left(\mathrm{Mo}_{2}\right)$} \\
\hline & $\mathrm{Mo}_{2}-\mathrm{S}_{12} 2.438(3)$ & $\mathrm{S}_{12}-\mathrm{C}_{31} 1.727(10)$ & & \\
\hline \multirow{2}{*}{$\mathrm{Cp}_{2} \mathrm{Mo}(\mathrm{sdt})^{22}$} & $\mathrm{Mo}_{1}-\mathrm{S}_{1} 2.4402(7)$ & S-C 1.771(3) & \multirow[t]{2}{*}{$1.327(3)$} & \multirow[t]{2}{*}{ planar } \\
\hline & $\mathrm{Mo}_{1}-\mathrm{S}_{2} 2.4396(7)$ & S-C $1.746(3)$ & & \\
\hline
\end{tabular}


For both complexes, the $\mathrm{MoS}_{2} \mathrm{C}_{2}$ metallacycles are nearly planar with a folding angle $\theta$, along the S $\bullet \cdot S$ hinge of the metallacycle, in the range of $2.6-5.1^{\circ}$, in line with the corresponding values obtained $\mathrm{Cp}_{2} \mathrm{Mo}(\mathrm{bdt})^{21}$ and $\mathrm{Cp}_{2} \mathrm{Mo}(\mathrm{sdt}) .{ }^{22}$ The bond lengths and bond angles of the metallacycles are also in the range of those found for the monometallic references compounds. $^{21,22}$ (Table 1). In both complexes the organic spacers are not planar. Indeed, in Mo2L1 a dihedral angle of $41.9(1)^{\circ}$ is observed between the two phenyl rings and in $\mathbf{M o} \mathbf{L} 2$ the two dihedral angles between the $\mathrm{C}_{2} \mathrm{~S}_{2}$ planes and the phenyl ring reach $28.9(3)^{\circ}\left(\mathrm{Mo}_{1}\right)$ and $26.7(3)^{\circ}\left(\mathrm{Mo}_{2}\right)$.
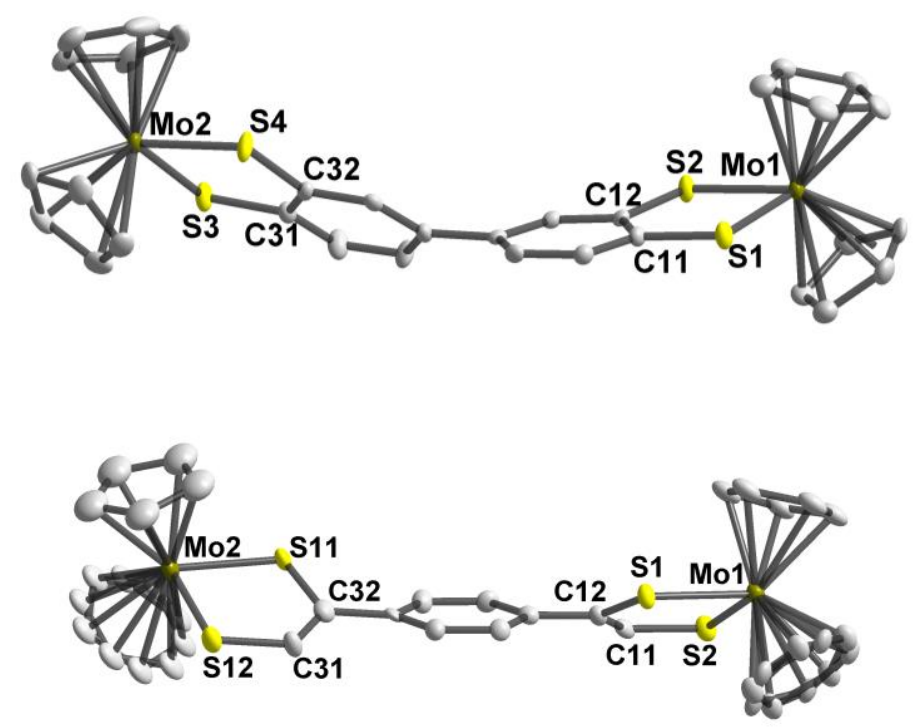

Figure 2 Molecular structures of the two complexes, $\mathbf{M o}_{2} \mathbf{L 1}$ (top) and $\mathbf{M o}_{2} \mathbf{L 2}$ (bottom). Thermal ellipsoids are drawn at 50\% probability level. $\mathrm{H}$ atoms have been omitted for clarity.

Electrochemical investigations. The redox properties of SnL1Mo, Mo2L1 and Mo2L2 were evaluated by cyclic voltammetry $(\mathrm{CV})$ performed in $\mathrm{CH}_{2} \mathrm{Cl}_{2}$ in the presence of $0.1 \mathrm{M}$ of $\mathrm{NBu}_{4} \mathrm{PF}_{6}$ as supporting electrolyte. $\mathrm{CV}$ s are reported in Figure 3 while the deduced half-wave redox potentials are summarized in Table 2. $\mathrm{Cp}_{2} \mathrm{Mo}$ (dithiolene) complexes are known to be reversibly oxidized into a cation radical and a dicationic species. Considering the 
monosubstituted $\mathrm{Cp}_{2} \mathrm{Mo}$ biphenyl SnL1Mo, the $\mathrm{CV}$ indeed displays two reversible monoelectronic oxidation waves. As the oxidation of $\mathbf{S n}_{2} \mathbf{L} \mathbf{1}$ occurs at a higher potential, 1.1 V vs SCE, (see SI), the two redox processes are attributed to the oxidation of the $\mathrm{Cp}_{2} \mathrm{Mo}$ (dithiolene) moiety into the radical cation and dicationic species. (Figure 3A, red CV). For the complexes with two $\mathrm{Cp}_{2} \mathrm{Mo}$ (dithiolene) units, two types of behavior can be envisioned. If the two $\mathrm{Cp}_{2} \mathrm{Mo}$ (dithiolene) moieties of each complex behave independently, both electrophores should be oxidized at the same potential leading to only two redox waves on the CV. Contrariwise, if electronic interactions occur between the two metalladithiolene units, then the oxidation of those moieties should occur separately at different potentials leading to multi redox processes.
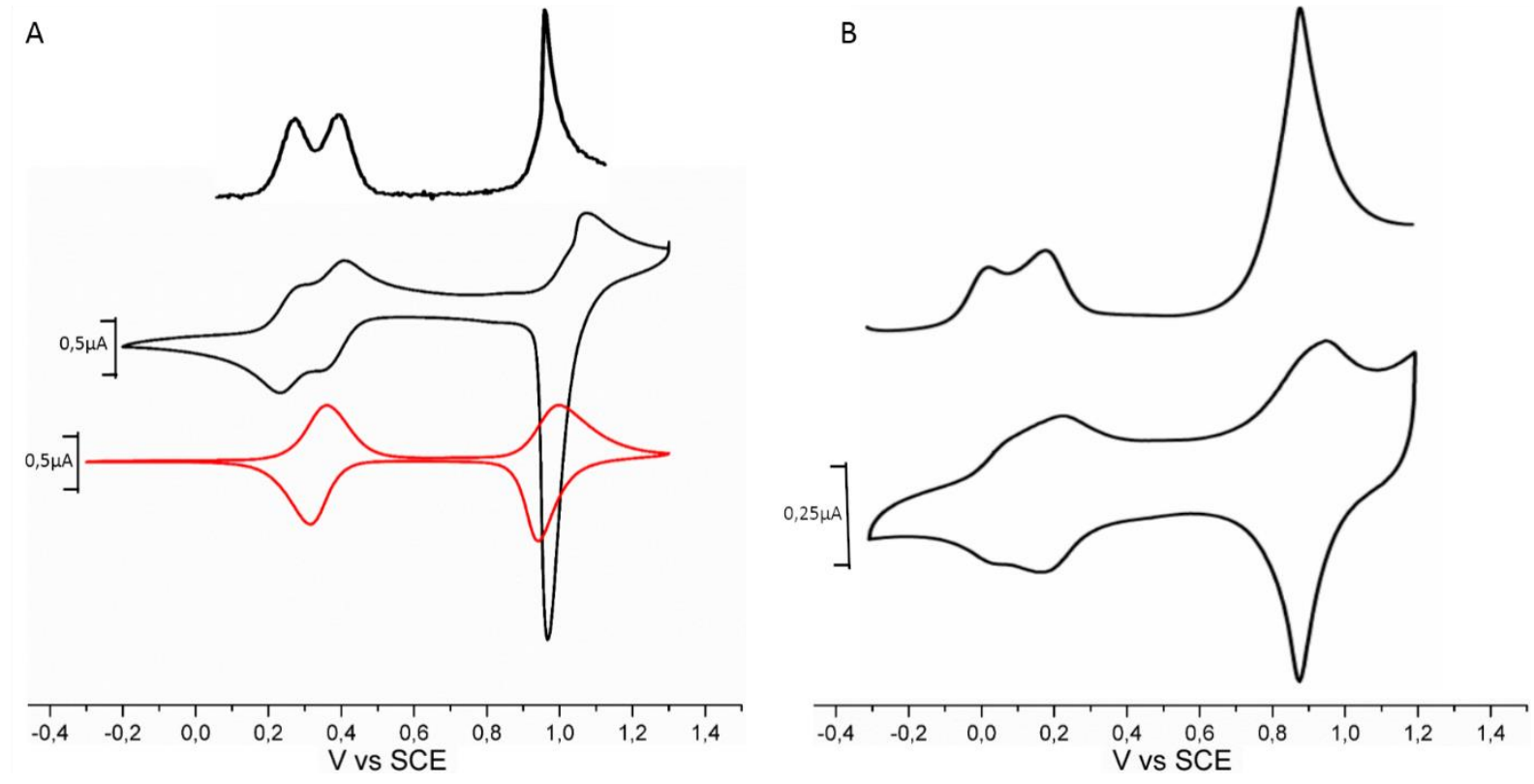

Figure 3. Cyclic voltammograms and Differential Pulse Voltammetry (DPV, top) of Mo2L1 (A, black), Mo2L2 (B) and cyclic voltammogram SnL1Mo (A, red) in $\mathrm{CH}_{2} \mathrm{Cl}_{2}$ $\mathrm{Bu}_{4} \mathrm{NPF}_{6} 0.1 \mathrm{M}(100 \mathrm{mV} / \mathrm{s})$.

Here, for both bimetallic complexes $\mathbf{M o}_{2} \mathbf{L} 1$ and $\mathbf{M o}_{2} \mathbf{L} 2$, the CVs display multi redox processes suggesting a sizeable electronic interaction between the two $\mathrm{Cp}_{2} \mathrm{Mo}$ (dithiolene) moieties 
through the organic linker. In both cases, the first two processes are fully reversible $\left(E_{1}=0.25\right.$ $\mathrm{V}$ and $\mathrm{E}_{2}=0.37 \mathrm{~V} v s$. SCE for $\mathbf{M o}_{2} \mathbf{L} \mathbf{1} ; \mathrm{E}_{1}=0.03 \mathrm{~V}$ and $\mathrm{E}_{2}=0.19 \mathrm{~V} v s$. SCE for Mo2L2) as shown in Figure 3. This indicates the stepwise oxidation of each neutral $\mathrm{Cp}_{2} \mathrm{Mo}$ (dithiolene) moiety into the radical cation. The other oxidation processes occur at a more anodic potential and the shape of these broad waves indicates the adsorption of an oxidized species on the electrode followed by a sharp desorption reduction peak. Thus, the CVs of the two bimetallic complexes $\mathbf{M o}_{2} \mathbf{L} 1$ and $\mathbf{M o}_{2} \mathbf{L} 2$ show two well defined redox processes followed by a third and broad one involving adsorption at the electrode. This is also confirmed by Differential Pulse Voltammetry (DPV) (Inserts in Figure 3). The redox potentials and the potential difference between the redox processes vary significantly between these two complexes which were analyzed in the same conditions (Table 2). Due to the presence of the two electron rich $\mathrm{Cp}_{2} \mathrm{Mo}$ (dithiolene) moieties, the first redox process of the bimetallic complex $\mathbf{M o 2} \mathbf{L} \mathbf{1}$ occurs at a less anodic potential than that of the monosubstituted one $\operatorname{SnL1Mo}\left(\mathrm{E}_{1}=0.25 \mathrm{~V}\right.$ for Mo2 $\mathbf{L} \mathbf{1}$ and $\mathrm{E}_{1}=0.34 \mathrm{~V} v s . \mathrm{SCE}$ for SnL1Mo). In addition, comparison between the two bimetallic complexes highlights the effect of the fusion between the phenyl ring and the $\mathrm{Cp}_{2} \mathrm{Mo}$ (dithiolene) moiety as there is an anodic shift of about $220 \mathrm{mV}$ of the first anodic process for $\mathbf{M o}_{2} \mathbf{L} 1\left(\mathrm{E}_{1}=0.25 \mathrm{~V}\right.$ vs. SCE$)$ compared to $\mathbf{M o}_{2} \mathbf{L} 2\left(\mathrm{E}_{1}=0.03 \mathrm{~V}\right.$ vs. SCE$)$. Concerning the potential difference between the first two redox processes $\left(\Delta \mathrm{E}_{1 / 2}=\mathrm{E}_{1 / 2}{ }^{2}-\mathrm{E}_{1 / 2}{ }^{1}\right)$, it amounts to $120 \mathrm{mV}$ for $\mathbf{M o}_{2} \mathbf{L} \mathbf{1}$ while $\Delta \mathrm{E}_{1 / 2}$ reaches $160 \mathrm{mV}$ for $\mathbf{M o}_{2} \mathbf{L} 2$. This result is in stark contrast with that obtained for the tetrametallic Mo complex (shown in Chart 1$)^{11}$ where no electronic interaction along the bridging ligand $\left((\mathbf{M e 3} \mathbf{S i})_{2} \mathbf{L} 2\right)$ was detected by cyclic voltammetry. The $\Delta \mathrm{E}_{1 / 2}$ values measured in the same conditions $\left(\mathrm{CH}_{2} \mathrm{Cl}_{2}-\mathrm{Bu}_{4} \mathrm{NPF}_{6} 0.1 \mathrm{M}\right)$ can be compared ${ }^{23}$ and correspond to comproportionation constants, $K c$, in the same range for both complexes namely $1 \times 10^{2}$ and $5 \times 10^{2}$ for $\mathbf{M o}_{2} \mathbf{L} 1$ and $\mathbf{M o}_{2} \mathbf{L} 2$ respectively. Charge transfer in mixed valence molecules is often considered to depend on the distances between both redox active sites. ${ }^{24}$ 
Here, the intramolecular Mo-Mo distance reaches $12.75 \AA$ and $12.32 \AA$ for $\mathbf{M o}_{2} \mathbf{L} 1$ and $\mathbf{M o} 2 \mathbf{L} 2$ respectively. These very close distances are in accordance with the slight difference obtained in the respective $K c$ values. These values are nevertheless much lower than those found for some bimetallic complexes ${ }^{6}$ of the benzenetetrathiolate (btt) ligand which exhibit much shorter M-M distances $\left(\sim 8.45 \AA\right.$ ) (e.g. $K c=1.610^{11}$ also determined in $\mathrm{CH}_{2} \mathrm{Cl}_{2}-\mathrm{Bu}_{4} \mathrm{NPF}_{6} 0.1 \mathrm{M}$ for compound $3 \mathrm{~d}$ in reference $6 \mathrm{c})$.

Table 2. Half-wave redox potentials ${ }^{a}$ of complexes, SnL1Mo, $M o 2 L 1$ and $\mathbf{M o}_{2} \mathbf{L} 2$ in $\mathrm{CH}_{2} \mathrm{Cl}_{2}$ ( $\mathrm{E}$ in $\mathrm{V}$ vs SCE).

\begin{tabular}{cccc}
\hline Compound & $\mathrm{E}_{1 / 2}{ }^{1}(\Delta \mathrm{Ep})^{\mathrm{b}}$ & $\mathrm{E}_{1 / 2}{ }^{2}(\Delta \mathrm{Ep})$ & $\mathrm{E}_{\mathrm{pa}} / \mathrm{E}_{\mathrm{pc}}{ }^{3}(\Delta \mathrm{Ep})$ \\
\hline SnL1Mo & $0.34(60)$ & $0.97(60)$ & \\
Mo2L1 & $0.25(60)$ & $0.37(60)$ & $1.07 / 0.97(100)$ \\
$\mathbf{M o 2} \mathbf{L 2}$ & $0.03(60)$ & $0.19(60)$ & $0.95 / 0.88(70)$ \\
$\mathrm{Cp}_{2} \mathrm{Mo}(\mathrm{sdt})^{\mathrm{c}, 22}$ & 0.34 & - & - \\
\hline
\end{tabular}

${ }^{\mathrm{a}}$ oxidation processes, taken as the average of the anodic and the cathodic peak potentials. ${ }^{\mathrm{b}} \Delta E_{\mathrm{p}}$ (in $\mathrm{mV}$ ) : peak-to-peak separation. ${ }^{\mathrm{c}}$ Analysed in DMF.

Spectroelectrochemical studies. UV-vis-NIR spectroelectrochemical investigations were performed on dichloromethane solution of the three SnL1Mo, Mo2L1 and Mo2L2. These three neutral complexes exhibit absorption bands in the UV-vis range only. The lowest energy band in these neutral complexes is assigned to a ligand-metal charge transfer (LMCT) band from dithiolene to Mo. ${ }^{25}$ The LMCT nature of the low energy absorption band has been confirmed with TD-DFT calculations on $\mathbf{M o}_{2} \mathbf{L} 1$ and $\mathbf{M o 2} \mathbf{L 2}$ (see supporting information). Gradual oxidation of the monosubsituted complex SnL1Mo to the monocation radical species 
leads to the growth of new absorption bands centered at $670 \mathrm{~nm}$ and $1140 \mathrm{~nm}$, as typically observed with $\mathrm{Cp}_{2} \mathrm{Mo}$ (dithiolene) complexes. ${ }^{22,26}$

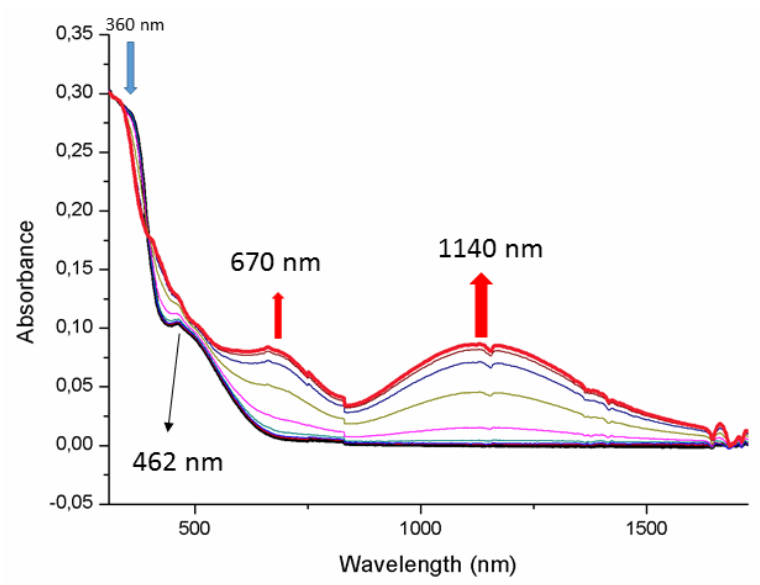

Figure 4 UV-vis-NIR absorption spectra of complex SnL1Mo monitored from the neutral state to the monocation radical state upon electrochemical oxidation.

The spectra recorded upon oxidation from the neutral to the monocationic state of the bimetallic complexes Mo2L1 and Mo2L2 show different features. Indeed, the gradual oxidation of $\mathbf{M o}_{2} \mathbf{L} \mathbf{1}$ to the monocationic species leads to the growth of new absortion bands in the visible region at 476 and $702 \mathrm{~nm}$ together with the appearance of a weak absorption at $998 \mathrm{~nm}$ and a broader one centered at $1596 \mathrm{~nm}$ in the NIR region (Figure 5), the latter being ascribed to the signature of a mixed valence species. Continued gradual oxidation to the bis(cationic) species induces the decrease of the bands observed in the NIR together with the appearance of a new absorption band centered at $1170 \mathrm{~nm}$. It is interesting to compare the evolution of the absorption spectra of Mo2L1 upon gradual oxidation with those of complex SnL1Mo where only one Mo atom is connected to a dithiolene group. The signature of the single cation radical species in SnL1Mo (Figure 4) is similar to that observed for the biscationic species in Mo2L1 (Figure 5, right) suggesting close electronic structures. DFT calculations on $\mathbf{M o}_{2} \mathbf{L 1}^{2+}$ show that the triplet state is more stable by $0.25 \mathrm{eV}$ compared to the singlet state so that $\mathbf{M o}_{2} \mathbf{L} \mathbf{1}^{\mathbf{2 +}}$ can be consistently described as a dication diradical. 

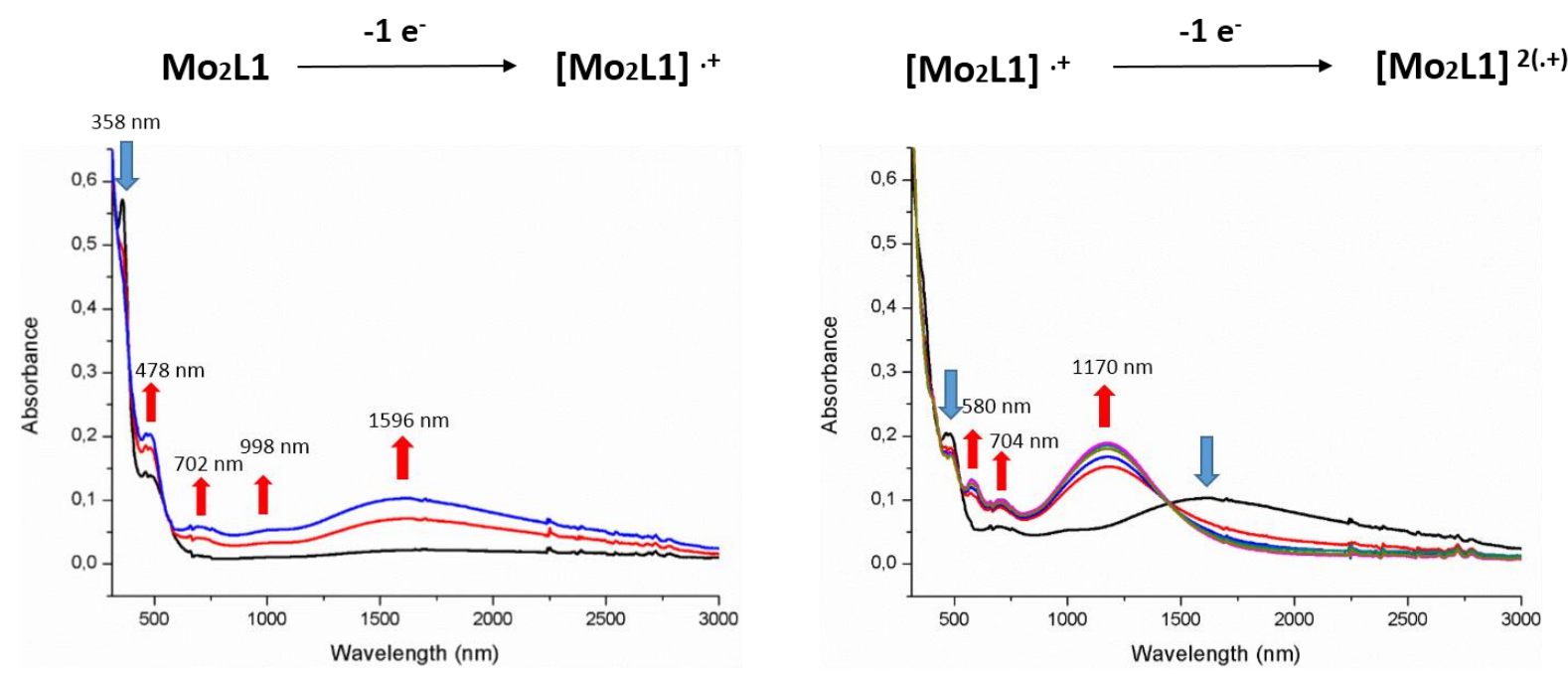

Figure 5 UV-vis-NIR absorption spectra monitored from the neutral state to the monocationic state (left) and from the monocationic state to the biscationic state (right) upon electrochemical oxidation of $\mathbf{M o}_{2} \mathbf{L} 1$.

Investigations carried out on $\mathbf{M o}_{2} \mathbf{L} 2$ show similar trends (Figure 6). Gradual oxidation to the monocation radical species of $\mathbf{M o 2} \mathbf{L} 2$ leads to the growth of new absorption bands centered at 534 and $632 \mathrm{~nm}$ together with a broad one in the NIR region. The latter is again ascribed to the formation of a mixed valence species. This band can tentatively be deconvoluted into two bands centered at $1732 \mathrm{~nm}$ and $2493 \mathrm{~nm}$. Then, upon oxidation to the biscationic species, the intensity of these bands observed in the NIR region vanish gradually giving way to the emergence of two new bands centered at 870 and $1154 \mathrm{~nm}$. An isosbestic point at $1318 \mathrm{~nm}$ evidences the co-existence of the two different species in the medium (cation radical and dication diradical). There again the spectrum of the bis oxidized species of $\mathbf{M o z}_{2} \mathbf{L} 2$ shows some close similarities with that of the cation radical species of SnMoL1. 

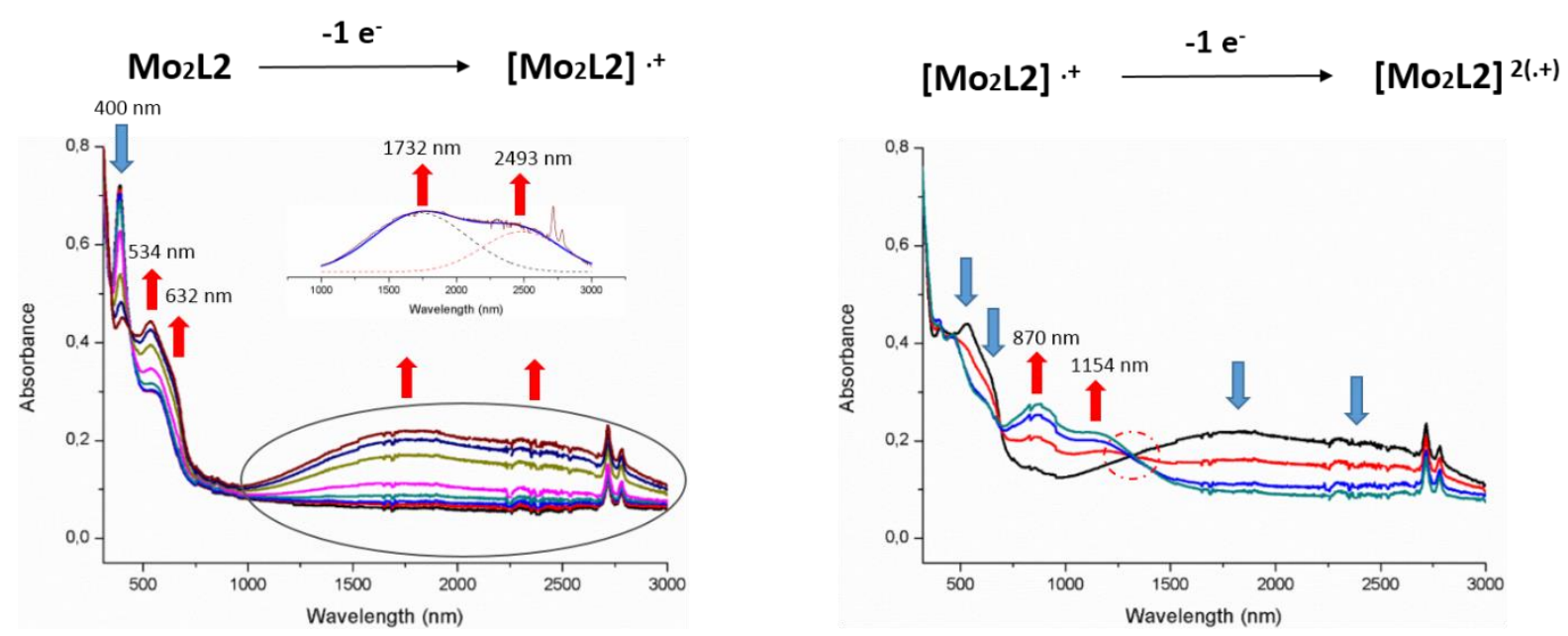

Figure 6 UV-vis-NIR absorption spectra monitored from the neutral state to the monocationic state (left) from the monocationic state to the biscationic state (right) upon electrochemical oxidation of $\mathbf{M o 2} \mathbf{L} 2$.

Thus, the band observed at lower energy upon the gradual oxidation of $\mathbf{M o z}_{2} \mathbf{L} \mathbf{1}$ and Mo2L2 to the monooxidized species can be viewed as an intervalence charge-transfer (IVCT), in line with the $\mathrm{CV}$ analysis. To further characterize this electronic communication between the two $\mathrm{Cp}_{2} \mathrm{Mo}$ (dithiolene) moieties along the organic bridge DFT and TD-DFT calculations were carried out on these two bimetallic complexes.

DFT and TD-DFT calculations. Geometry optimizations carried out on Mo2L1 and Mo2L2 in the neutral state [Gaussian03, B3LYP/LanL2DZ] lead to a slightly folded $\mathrm{MoS}_{2} \mathrm{C}_{2}$ metallacycle and a HOMO delocalized over the whole organic spacer with little metal contribution (Figure 7). The agreement of the experimental and calculated bond lengths for the neutral species is reasonably good (calculated bond distances and angles are reported in Tables $\mathrm{S} 1$ and S2 in the supporting information). The LUMO of both complexes are centered essentially on the molybdenocene moiety at near identical energy level (ca. $-2 \mathrm{eV}$ ). The calculated energy level for the HOMO in $\mathbf{M o}_{2} \mathbf{L} 2(-4.27 \mathrm{eV})$ is notably higher in energy by 0.22 
$\mathrm{eV}$ than that of the HOMO in $\mathbf{M o z} \mathbf{L 1}(-4.49 \mathrm{eV})$ in perfect accordance with the relative redox potentials differing by $220 \mathrm{mV}$ determined by cyclic voltammetry $(0.03 \mathrm{~V}$ vs. $0.25 \mathrm{~V}$ respectively, vide supra).
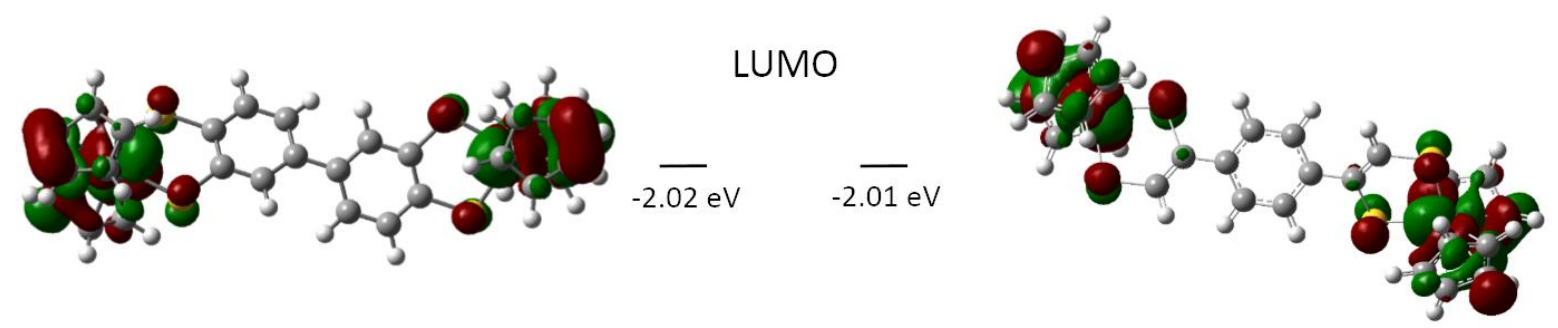

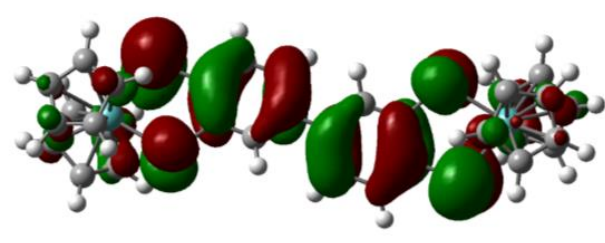

Mo2L1

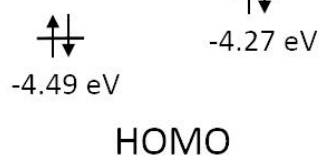

Neutral species

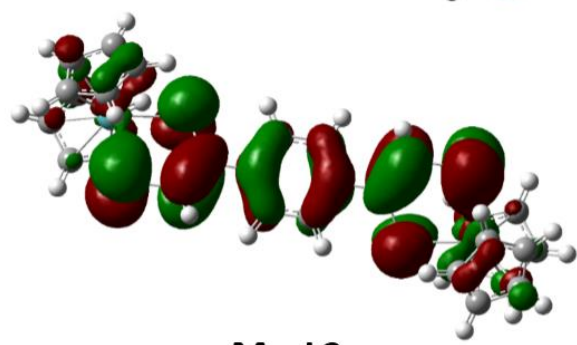

Mo2L2

Figure 7 Frontier molecular orbitals (HOMO and LUMO) and calculated energy levels for complexes Mo2L1 (left) and Mo2L2 (right) shown with a cutoff of 0.04 [e/bohr $\left.{ }^{3}\right]^{1 / 2}$.

In the radical cation state as well as in the bis(oxidized) one, both complexes exhibit a planarization of the $\mathrm{MoS}_{2} \mathrm{C}_{2}$ metallacycle and a SOMO delocalized on the bisdithiolene organic spacer with no or very little contribution of the metal (Figure 8). Moreover, upon oxidation to the monocation, for both complexes a planarization of the organic spacers is observed with reduced dihedral angles either between the two phenyl rings by $8^{\circ}$ in $\mathbf{M o}_{2} \mathbf{L} \mathbf{1}$ or between the $\mathrm{C}_{2} \mathrm{~S}_{2}$ planes and the phenyl ring by $7^{\circ}$ in $\mathbf{M o 2} \mathbf{L} 2$ (see SI). Interestingly, in these optimized structures the bond lengths evolution of the dithiolene moieties shows a decrease of the C-S distances together with an increase of the C-C bond lengths (Table S1 and S2). These observations are in excellent agreement with a primarily ligand based electron transfer. 


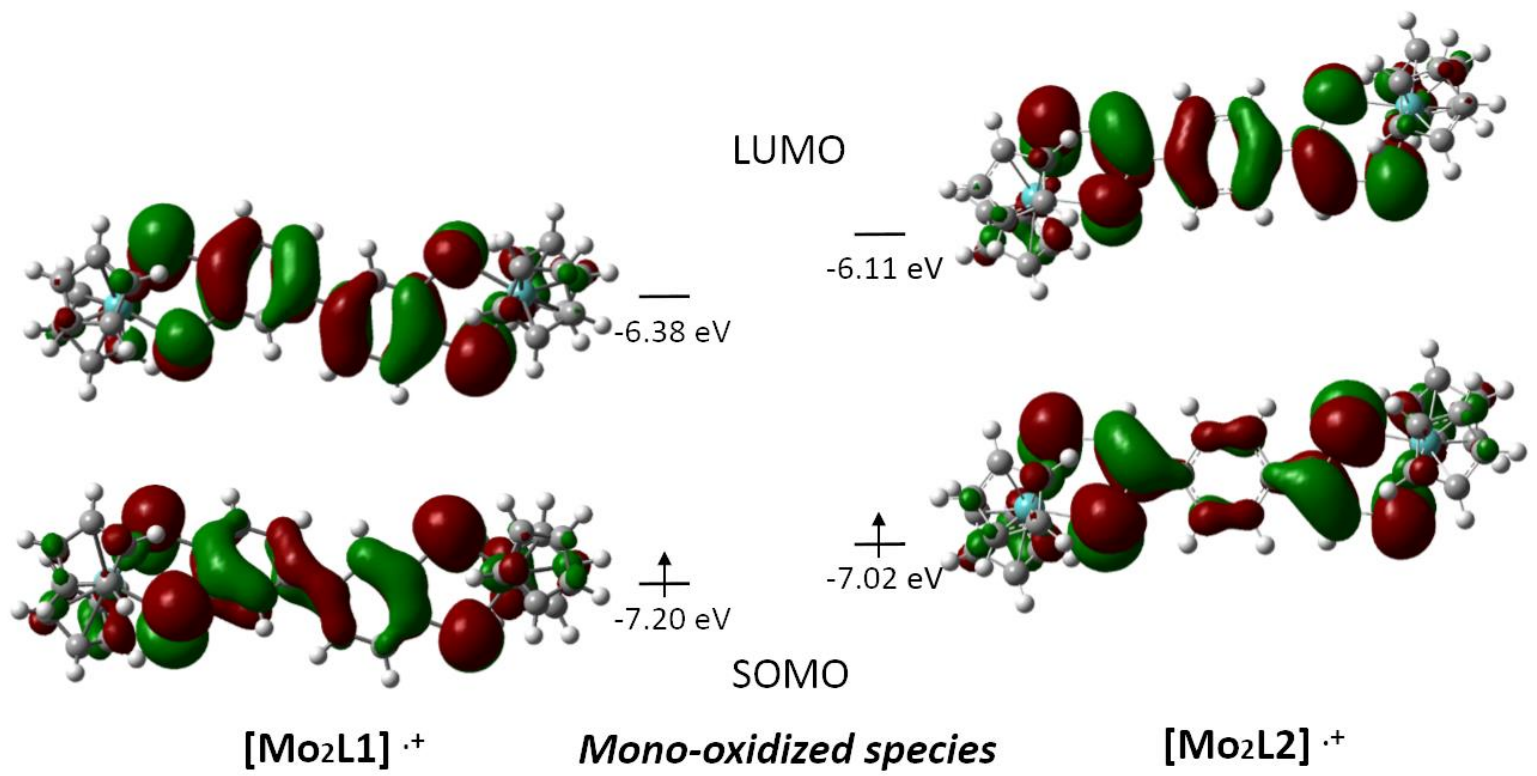

Figure 8 Frontier molecular orbitals (SOMO and LUMO) of the monooxidized species and calculated energy levels for complexes Mo2L1 (left) and Mo2L2 (right) shown with a cutoff of $0.04\left[\mathrm{e} / \mathrm{bohr}^{3}\right]^{1 / 2}$.

TD-DFT calculations on optimized geometry of the doublet state of monocationic $\mathbf{M o z}_{\mathbf{L}} \mathbf{L} \mathbf{1}$ and Mo2L2 identify an intense and broad low energy transition with a significant oscillator strength. For both monocationic complexes the major contribution in this low energy transition arises from the frontier spin orbitals, both essentially delocalized over the bridging ligand and with negligible contribution from the metallocene moieties. This is consistent with the assignment of this band as being an IVCT from spectroelectrochemical investigations (vide supra). For both cations of $\mathbf{M o}_{2} \mathbf{L} 1$ and $\mathbf{M o}_{2} \mathbf{L} 2$ the IVCT is proposed to be ligand centered (intra-ligand charge transfer) with the metallocene moieties playing the role of 'anchors' and electron donors for the non-innocent bisdithiolene bridging ligand. ${ }^{3,4}$

\section{Conclusion}

Bimetallic complexes involving biscyclopentadienyl Mo(dithiolene) moieties namely $\left(\mathrm{Cp}_{2} \mathrm{Mo}\right)_{2}(\mathrm{dbdt})$ and $\left(\mathrm{Cp}_{2} \mathrm{Mo}\right)_{2}(\mathrm{bdedt})(\mathbf{M o} 2 \mathbf{L 1}$ and $\mathbf{M o} \mathbf{L} \mathbf{L} 2$ respectively) have been synthetized. The $\mathrm{Cp}_{2} \mathrm{Mo}$ (dithiolene) fragment was selected for its well-known and easily accessible redox 
activity and the two organic linkers for their possible structural flexibility despite their conjugated skeleton. Two types of proligands have been evaluated: either the bisdithiolene protected by a carbonyl group or by a dialkyltin one. Transmetallation of the dialkyltin group in $\mathbf{S n} 2 \mathbf{L 1}$ in the presence of $\mathrm{Cp}_{2} \mathrm{MoCl}_{2}$ afforded the desired $\mathbf{M o}_{2} \mathbf{L} \mathbf{1}$ complex whereas it turned out that with the second protected ligand $\mathbf{S n}_{2} \mathbf{L} 2$ no bimetallic complex was obtained. However, Mo2L2 was successfully prepared through the use of the dithiole-2-one pro-ligand. Electrochemical and UV-vis-NIR spectroelectrochemical investigations have evidenced electronic interactions between the two organometallic electrophores along the organic linker. This can be detected electrochemically by the sequential oxidation of each $\mathrm{Cp}_{2} \mathrm{Mo}$ (dithiolene) moiety with a $\Delta \mathrm{E}_{1 / 2}$ value of 120 and $160 \mathrm{mV}$. The recorded spectra of the monocharged species evidenced a broad absorption band assigned to an intervalence charge transfer band (IVCT). DFT calculations suggest that this IVCT can be better described as an essentially bridging ligand-based process assisted by the electron rich metallocene moieties anchored to the linker through the non-innocent bisdithiolene fragments.

\section{Experimental section}

General. NMR spectra were recorded at room temperature using $\mathrm{CDCl}_{3}$ unless otherwise noted. Chemical shifts are reported in ppm and ${ }^{1} \mathrm{H}$ NMR spectra were referenced to residual $\mathrm{CHCl}_{3}(7.26 \mathrm{ppm})$ and ${ }^{13} \mathrm{C} \mathrm{NMR}$ spectra were referenced to $\mathrm{CHCl}_{3}(77.2 \mathrm{ppm})$. Mass spectra were recorded with Agilent 6510 instrument for organics compounds, and with ThermoFisher Q-Exactive instrument for complexes by the Center Régional de Mesures Physiques de l'Ouest, Rennes. CVs were carried out on a $10^{-3} \mathrm{M}$ solution of complex in $\mathrm{CH}_{2} \mathrm{Cl}_{2}-\left[\mathrm{NBu}_{4}\right]\left[\mathrm{PF}_{6}\right]$ 0.1 M. CVs were recorded on a Biologic SP-50 instruments at $0.1 \mathrm{Vs}^{-1}$ on a platinum disk electrode. Potentials were measured versus $\mathrm{KCl}$ Saturated Calomel Electrode (SCE). The spectroelectrochemical setup was performed in $\mathrm{CH}_{2} \mathrm{Cl}_{2}-\left[\mathrm{NBu}_{4}\right]\left[\mathrm{PF}_{6}\right] 0.2 \mathrm{M}$ using a Pt grid as 
the working electrode, a Pt wire as the counter electrode and SCE reference electrode. A Shimadzu 3600 plus spectrophotometer was employed to record the UV-vis-NIR spectra. Column chromatography was performed using silica gel Merck 60 (70-260 mesh). All reagents and materials from commercial sources were used without further purification. The complexes were synthetized under an argon atmosphere using standard Schlenk techniques. The solvents were purified and dried by standard methods. Compound 2 was synthesized according to literature procedure. ${ }^{10}$

Synthesis of 4,4'-(1,4-phenylene)bis-1,3-dithiol-2-one $\quad 2$. To a solution of 1,4bis(bromoacetyl)benzene 1 (4.00 g, $12.5 \mathrm{mmol})$ in $150 \mathrm{~mL}$ of dichloromethane was added potassium isopropylxanthate $(4.35 \mathrm{~g}, 25.0 \mathrm{mmol})$. The mixture was stirred for one hour, and the precipitate of $\mathrm{KBr}$ that formed was separated by filtration through Celite and washed with $\mathrm{CH}_{2} \mathrm{Cl}_{2}(100 \mathrm{~mL})$. The combined washing and filtrate were then taken to dryness under reduced pressure to afford the xanthate ester as a bright yellow solid (5.37 g), which was used without further purification. $\mathrm{Mp}=136^{\circ} \mathrm{C} ;{ }^{1} \mathrm{H} \mathrm{NMR}(300 \mathrm{MHz}) \delta 1.37\left(\mathrm{~d}, 12 \mathrm{H},{ }^{3} \mathrm{~J}=6.2 \mathrm{~Hz}, \mathrm{CH}_{3}\right), 4.64$ (s, 4H, CH ), 5.70 (hept, $\left.2 \mathrm{H},{ }^{3} \mathrm{~J}=6.2 \mathrm{~Hz}, \mathrm{C} \underline{\mathrm{H}}\left(\mathrm{CH}_{3}\right)_{2}\right), 8.12$ (s, 4H, Ar); ${ }^{13} \mathrm{C} \mathrm{NMR}\left(\left(\mathrm{CD}_{3}\right)_{2} \mathrm{SO}\right.$, $101 \mathrm{MHz}, \mathrm{T}=383 \mathrm{~K}) \delta 21.3\left(\mathrm{CH}_{3}\right), 43.3\left(\mathrm{CH}_{2}\right), 79.3\left(\underline{\mathrm{CH}}\left(\mathrm{CH}_{3}\right)_{2}\right), 128.9(4 \mathrm{Ar}), 139.5(2 \mathrm{Ar})$, 192.1 $(\mathrm{C}=\mathrm{O}), 212.1(\mathrm{C}=\mathrm{S})$; HRMS (ESI) calcd for $\mathrm{C}_{18} \mathrm{H}_{22} \mathrm{O}_{4} \mathrm{NaS}_{4}[\mathrm{M}+\mathrm{Na}]^{+}$: 453.02932 . Found: 453.0295. To $100 \mathrm{~mL}$ of concentrated sulfuric acid was slowly dropped at $0^{\circ} \mathrm{C}$ the xanthate ester $(5.37 \mathrm{~g}, 12.5 \mathrm{mmol})$. The solution was stirred 6 hours at $0^{\circ} \mathrm{C}$ and poured in $800 \mathrm{~mL}$ of iced water. The precipitate was filtered off and washed with water and ethanol. The precipitate was dried overnight in oven to afford 4,4'-(1,4-phenylene)bis-1,3-dithiol-2-one 2 (3.13 g, 10.1 mmol) as light beige solid. Crystals of sufficient quality for X-ray diffraction were obtained by slow evaporation of a toluene solution. Yield: $81 \% ; \mathrm{Mp}=214{ }^{\circ} \mathrm{C} ;{ }^{1} \mathrm{H} \mathrm{NMR}\left(\left(\mathrm{CD}_{3}\right)_{2} \mathrm{SO}, 300\right.$ $\mathrm{MHz}) \delta 7.65(\mathrm{~s}, 4 \mathrm{H}, \mathrm{Ar}), 7.76(\mathrm{~s}, 2 \mathrm{H},=\mathrm{CH}) ;{ }^{13} \mathrm{C} \mathrm{NMR}\left(\left(\mathrm{CD}_{3}\right)_{2} \mathrm{SO}, 100 \mathrm{MHz}\right) 114.7(\mathrm{~S} \underline{\mathrm{H}}=\mathrm{C})$, $126.4(4 \mathrm{Ar}), 131.8(2 \mathrm{Ar}), 132.1(\mathrm{SC}=\mathrm{CH}), 191.1(\mathrm{C}=\mathrm{O})$; HRMS (ESI) calcd for $\mathrm{C}_{12} \mathrm{H}_{6} \mathrm{O}_{2} \mathrm{NaS}_{4}$ 
$[\mathrm{M}+\mathrm{Na}]^{+}:$332.91484. Found: 332.9142; Anal calcd for $\mathrm{C}_{12} \mathrm{H}_{6} \mathrm{O}_{2} \mathrm{~S}_{4}: \mathrm{C}, 46.43 ; \mathrm{H}, 1.95 ; \mathrm{S}, 41.31$. Found: C, 46.18; H, 1.83; S, 40.77.

Synthesis of $\mathbf{S n} 2 \mathbf{L 2}$. To a flask containing 4,4'-(1,4-phenylene)bis-1,3-dithiol-2-one 2 (500 mg, $1.61 \mathrm{mmol}$ ) was added under inert atmosphere a solution of $\mathrm{NaOMe}$ (freshly prepared from sodium (220 mg, $9.67 \mathrm{mmol})$ in $25 \mathrm{~mL}$ of dry methanol). The reaction mixture was stirred for $1 \mathrm{~h} 30$ at $40^{\circ} \mathrm{C}$ then cooled at room temperature and $\mathrm{Bu}_{2} \mathrm{SnCl}_{2}(3.22 \mathrm{mmol}, 980 \mathrm{mg})$ was added. The reaction mixture was stirred overnight. The precipitate was filtered off and washed with water, ethanol and diethylether to afford compound $\mathbf{S} \mathbf{n}_{2} \mathbf{L} 2(500 \mathrm{mg}, 0.69 \mathrm{mmol}$ ) as a pale yellow powder. Crystals of sufficient quality for X-ray diffraction were obtained by slow evaporation of a dichloromethane solution. Yield: $43 \% ; \mathrm{Mp}=140^{\circ} \mathrm{C} ;{ }^{1} \mathrm{H}$ NMR $(300 \mathrm{MHz}) \delta 0.94(\mathrm{t}, 12 \mathrm{H}$, $\left.{ }^{3} J=7.3 \mathrm{~Hz}, \mathrm{CH}_{3}\right), 1.40\left(\mathrm{~m}, 8 \mathrm{H}, \mathrm{CH}_{3}-\underline{\mathrm{C}}_{2}\right), 1.53-1.67\left(\mathrm{~m}, 8 \mathrm{H}, \mathrm{CH}_{3}-\mathrm{CH}_{2}-\mathrm{C}_{2}\right), 1.68-1.79$ (m, 8H, Sn-CH 2$), 6.79(\mathrm{~s}, 2 \mathrm{H},=\mathrm{CH}), 7.47(\mathrm{~s}, 4 \mathrm{H}, \mathrm{Ar}) ;{ }^{13} \mathrm{C} \mathrm{NMR}(75 \mathrm{MHz}) \delta 13.6\left(\mathrm{CH}_{3}\right), 22.4\left(\mathrm{CH}_{3}-\right.$

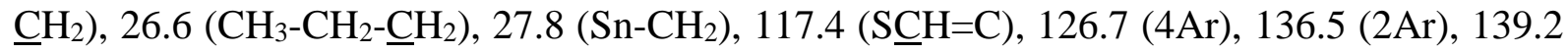
$(\mathrm{SC}=\mathrm{CH}) ; \mathrm{UV}$-vis $\left(\mathrm{CH}_{2} \mathrm{Cl}_{2}\right) \lambda_{\max }(\mathrm{nm})\left(\varepsilon\left[\mathrm{M}^{-1} . \mathrm{cm}^{-1}\right]\right)=247(25590), 346(19920) ;$ HRMS (ESI) calcd for $\mathrm{C}_{26} \mathrm{H}_{42} \mathrm{~S}_{4} \mathrm{NaSn}_{2}[\mathrm{M}+\mathrm{Na}]^{+}$: 745.01056. Found: 745.0107; Anal calcd for $\mathrm{C}_{26} \mathrm{H}_{42} \mathrm{~S}_{4} \mathrm{Sn}_{2}$ : C, 43.36; H, 5.88; S, 17.80. Found: C, 43.52; H, 5.69; S, 17.92.

Synthesis of SnL1Mo and MozL1. To a Schlenk tube, the bis(2,2-dimethyl[3,4-d]-1,3,2dithiastannolo)biphenyl $\mathbf{S n} 2 \mathbf{L 1}$ ( $200 \mathrm{mg}, 0.27 \mathrm{mmol}$ ) with $\mathrm{Cp}_{2} \mathrm{MoCl}_{2}$ (320 mg, $1.08 \mathrm{mmol}$ ) were placed under vacuum for $1 \mathrm{~h}$. Then the solids were solubilized in a dry and degassed mixture of $\mathrm{THF}$ and $\mathrm{CHCl}_{3}\left(10 \mathrm{~mL}\right.$ of each solvent). The solution was stirred overnight at $50^{\circ} \mathrm{C}$. The solvent was evaporated and the resulting solid was purified by flash chromatography on silica gel using chloroform/ethyl acetate (1/1) as eluent. Complexes SnL1Mo (30 mg, 0.04 mmol) and Mo2L1 (70 mg, $0.095 \mathrm{mmol}$ ) were obtained as dark red powder respectively in 15 and $35 \%$ yield. 
SnL1Mo: $(\mathrm{Rf}=0.2) ; \mathrm{Mp}=154^{\circ} \mathrm{C} ;{ }^{1} \mathrm{H}$ NMR $(300 \mathrm{MHz}) \delta 7.70(\mathrm{~d}, J=2.0 \mathrm{~Hz}, 1 \mathrm{H}), 7.56(\mathrm{~d}, J=$ $1.8 \mathrm{~Hz}, 1 \mathrm{H}), 7.41(\mathrm{dd}, J=23.6,8.1 \mathrm{~Hz}, 2 \mathrm{H}), 7.11(\mathrm{~m}, 1 \mathrm{H}), 6.95(\mathrm{~m}, 1 \mathrm{H}), 5.32(\mathrm{~s}, 10 \mathrm{H}), 1.80-$ $1.63(\mathrm{~m}, 8 \mathrm{H}), 1.42(\mathrm{~m}, 4 \mathrm{H}), 0.94(\mathrm{t}, J=7.3 \mathrm{~Hz}, 6 \mathrm{H}) ; \mathrm{NMR}{ }^{13} \mathrm{C}(75 \mathrm{MHz}) \delta 13.6\left(\mathrm{CH}_{3}\right), 21.9$ $\left(\mathrm{CH}_{3}-\underline{\mathrm{CH}}_{2}\right), 26.7\left(\mathrm{CH}_{3}-\mathrm{CH}_{2}-\underline{\mathrm{CH}}_{2}\right), 27.9\left(\mathrm{Sn}-\mathrm{CH}_{2}\right), 98.3$ (Cp), 120.7, 122.7, 126, 127.8, 128.1, $130(6 \mathrm{CH} \mathrm{Ar}), 134,136.1,137.4,138.6,144.6,145.8 ; \mathrm{UV}-\mathrm{vis}\left(\mathrm{CH}_{2} \mathrm{Cl}_{2}\right) \lambda_{\max }(\mathrm{nm})\left(\varepsilon\left[\mathrm{M}^{-1} . \mathrm{cm}^{-}\right.\right.$ $\left.\left.{ }^{1}\right]\right)=260(18161)$, 462(3004); HRMS (ESI) calcd for $\mathrm{C}_{30} \mathrm{H}_{34} \mathrm{~S}_{4} \mathrm{SnMo}[\mathrm{M}]^{+}:$739.96139. Found: 739.9617; Anal calcd for $\mathrm{C}_{30} \mathrm{H}_{34} \mathrm{~S}_{4}$ SnMo: C, 48.86; H, 4.65; S, 17.39. Found: C, 48.73; H, 4.70; S, 17.25.

Mo2L1: $(\mathrm{Rf}=0.5) ; \mathrm{Mp}>250{ }^{\circ} \mathrm{C} ;{ }^{1} \mathrm{H}$ NMR $(300 \mathrm{MHz}) \delta 7.58(\mathrm{~d}, J=1.9 \mathrm{~Hz}, 2 \mathrm{H}), 7.34(\mathrm{~d}, J=8.1$ $\mathrm{Hz}, 2 \mathrm{H}), 6.99(\mathrm{~m}, 2 \mathrm{H}), 5.31(\mathrm{~s}, 10 \mathrm{H}) .{ }^{13} \mathrm{C} \mathrm{NMR}$ spectrum could not be obtained due to limited solubility of the compound. UV-vis $\left(\mathrm{CH}_{2} \mathrm{Cl}_{2}\right) \lambda_{\max }(\mathrm{nm})\left(\varepsilon\left[\mathrm{M}^{-1} . \mathrm{cm}^{-1}\right]\right)=358(17400), 476(3757)$. HRMS (ESI) calcd for $\mathrm{C}_{32} \mathrm{H}_{26} \mathrm{~S}_{4} \mathrm{Mo}_{2}[\mathrm{M}]^{+}:$733.90255. Found: 733.9023; Anal calcd for $\left[\mathrm{C}_{32} \mathrm{H}_{26} \mathrm{~S}_{4} \mathrm{Mo}_{2}+1 / 2 \mathrm{CH}_{2} \mathrm{Cl}_{2}\right]: \mathrm{C}, 50.49 ; \mathrm{H}, 3.52 ; \mathrm{S}, 16.59$. Found: C, 50.81; H, 3.86; S, 16.32.

Synthesis of Mo2L2. To a flask containing bis-dithiolone 1 (180 mg, $0.58 \mathrm{mmol})$ was added under inert atmosphere a solution of $\mathrm{NaOMe}$ (freshly prepared from sodium $(80 \mathrm{mg}, 3.48$ mmol) in $15 \mathrm{~mL}$ of dry methanol). The reaction mixture was stirred for $1 \mathrm{~h} 30$ at $40^{\circ} \mathrm{C}$ then cooled at room temperature and $\mathrm{Cp}_{2} \mathrm{MoCl}_{2}(1.16 \mathrm{mmol}, 344 \mathrm{mg})$ was added. The reaction mixture was heated at $60^{\circ} \mathrm{C}$ overnight. The precipitate was filtered off and washed with water, ethanol and diethylether to afford compound $\mathbf{M o 2} \mathbf{L 2}(350 \mathrm{mg}, 0.49 \mathrm{mmol}$ ) as a black powder. Crystals of sufficient quality for X-ray diffraction were obtained by slow evaporation of a saturated chloroform solution. Yield: $85 \% ; \mathrm{Mp}>250{ }^{\circ} \mathrm{C} ;{ }^{1} \mathrm{H} \mathrm{NMR}\left(\left(\mathrm{CD}_{3}\right)_{2} \mathrm{SO}, 300 \mathrm{MHz}\right) \delta 5.35$ (s, 20H, Cp), $6.67(\mathrm{~s}, 2 \mathrm{H},=\mathrm{CH}), 7.41(\mathrm{~s}, 4 \mathrm{H}, \mathrm{Ar}) ;{ }^{13} \mathrm{C}$ NMR spectrum could not be obtained due to limited solubility of the compound; UV-vis $\left(\mathrm{CH}_{2} \mathrm{Cl}_{2}\right) \lambda_{\max }(\mathrm{nm})\left(\varepsilon\left[\mathrm{M}^{-1} \cdot \mathrm{cm}^{-1}\right]\right): 259$ (22100), 387(4000), 572(10940); HRMS (ESI) calcd for $\mathrm{C}_{30} \mathrm{H}_{26} \mathrm{~S}_{4} \mathrm{Mo}_{2}[\mathrm{M}]^{+}$: 709.90255. Found: 
709.9024; Anal calcd for $\left[\mathrm{C}_{30} \mathrm{H}_{26} \mathrm{~S}_{4} \mathrm{Mo}_{2}+1 / 2 \mathrm{CHCl}_{3}\right]$ : C, 48.05; H, 3.57; S, 17.27. Found: $\mathrm{C}$, 47.80; H, 3.49; S, 16.73.

\section{Crystallography}

Data were collected on a D8 VENTURE Bruker AXS diffractometer equipped with a (CMOS) PHOTON 100 detector, Mo-Ka radiation $(\lambda=0.71073 \AA$, multilayer monochromator) for 2 , $\operatorname{Sn}_{2} \mathbf{L} 2, M_{2} L 1$ and $M_{2} L 2$. The structures were solved by dual-space algorithm using the SHELXT program, ${ }^{27}$ and then refined with full-matrix least-square methods based on $F^{2}$ $\left(\right.$ SHELXL) ${ }^{28}$ For $\mathbf{M o} \mathbf{L} \mathbf{L}$, the contribution of the disordered solvents to the calculated structure factors was estimated following the BYPASS algorithm, ${ }^{29}$ implemented as the SQUEEZE option in PLATON.${ }^{30}$ A new data set, free of solvent contribution, was then used in the final refinement. For the four structures, all non-hydrogen atoms were refined with anisotropic atomic displacement parameters. $H$ atoms were finally included in their calculated positions. Crystallographic data on X-ray data collection and structure refinements are given in Table 3. 
Table 3 Crystallographic data for 2, $\operatorname{Sn}_{2} L 2, M_{2} L 1$ and $M_{2} L 2$

\begin{tabular}{|c|c|c|c|c|}
\hline Compound & 2 & $\mathbf{S n}_{2} \mathbf{L} 2$ & $\mathbf{M o}_{2} \mathbf{L} 1.0 .5 \mathrm{CH}_{2} \mathrm{Cl}_{2}$ & $\mathbf{M o}_{2} \mathbf{L} 2.0 .5 \mathrm{CHCl}_{3}$ \\
\hline Formula & $\mathrm{C}_{12} \mathrm{H}_{6} \mathrm{O}_{2} \mathrm{~S}_{4}$ & $\mathrm{C}_{26} \mathrm{H}_{42} \mathrm{~S}_{4} \mathrm{Sn}_{2}$ & $\mathrm{C}_{33} \mathrm{H}_{28} \mathrm{Cl}_{2} \mathrm{Mo}_{2} \mathrm{~S}_{4}$ & $\mathrm{C}_{31} \mathrm{H}_{27} \mathrm{Cl}_{3} \mathrm{Mo}_{2} \mathrm{~S}_{4}$ \\
\hline $\mathrm{FW}\left(\mathrm{g} \cdot \mathrm{mol}^{-1}\right)$ & 310.41 & 720.21 & 815.57 & 825.99 \\
\hline Crystal system & triclinic & triclinic & monoclinic & monoclinic \\
\hline Space group & $P-1$ & $P-1$ & $P 2_{1} / n$ & $P 2_{l} / c$ \\
\hline$a(\AA)$ & $3.9718(9)$ & $10.9394(14)$ & $13.5443(17)$ & $17.3775(17)$ \\
\hline$b(\AA)$ & $7.1545(14)$ & $13.0029(17)$ & $18.625(2)$ & $14.8924(13)$ \\
\hline$c(\AA)$ & $10.6205(17)$ & $13.3422(16)$ & $14.1052(17)$ & $11.7236(12)$ \\
\hline$\alpha\left({ }^{\circ}\right)$ & $80.822(7)$ & $65.420(4)$ & 90 & 90 \\
\hline$\beta\left(^{\circ}\right)$ & $79.994(8)$ & $76.584(4)$ & $115.704(4)$ & $96.300(4)$ \\
\hline$\gamma\left({ }^{\circ}\right)$ & $88.795(9)$ & $72.110(4)$ & 90 & 90 \\
\hline$V\left(\AA^{3}\right)$ & 293.39(10) & $1630.5(4)$ & $3206.0(7)$ & $3015.7(5)$ \\
\hline$T(\mathrm{~K})$ & $150(2)$ & 2 & $150(2)$ & $150(2)$ \\
\hline$Z$ & 1 & $250(2)$ & 4 & 4 \\
\hline$D_{\text {calc }}\left(\mathrm{g} \cdot \mathrm{cm}^{-3}\right)$ & 1.757 & 1.467 & 1.690 & 1.819 \\
\hline$\mu\left(\mathrm{mm}^{-1}\right)$ & 0.796 & 1.800 & 1.233 & 1.397 \\
\hline Total refls. & 5774 & 36783 & 31356 & 22944 \\
\hline Uniq. refls. $\left(R_{\text {int }}\right)$ & $1330(0.0781)$ & $7386(0.0504)$ & $7236(0.0799)$ & $6859(0.0666)$ \\
\hline $\begin{array}{c}\text { Unique } \\
\text { refls. }(\mathrm{I}>2 \mathrm{~s}(\mathrm{I}))\end{array}$ & 1139 & 5639 & 5458 & 4676 \\
\hline$R_{1}, w R_{2}$ & $0.0909,0.2900$ & $0.0580,0.1454$ & $0.0438,0.0981$ & $0.0846,0.1872$ \\
\hline $\begin{array}{c}R_{1}, w R_{2} \text { (all } \\
\text { data) }\end{array}$ & $0.1010,0.3015$ & $0.0807,0.1684$ & $0.0690,0.1090$ & $0.1320,0.2152$ \\
\hline GoF & 1.076 & 1.025 & 1.049 & 1.093 \\
\hline
\end{tabular}




\section{Acknowledgment}

This work was granted access to the computing resources of CINES (Montpellier, allocation 2019-A0060805032 awarded by GENCI).

\section{Supporting Information Available}

X-ray crystallographic files in CIF format, NMR, HRMS spectra and computational details. This material is available free of charge via the Internet at http://pubs.acs.org.

\section{Competing financial Interest}

The authors declare no competing financial interest.

\section{References}

1 Aguirre-Etcheverry, P.; O’Hare, D. Electronic communication through unsaturated hydrocarbon bridges in homobimetallic organometallic complexes. Chem. Rev. 2010, 110, 4839-4864.

${ }^{2}$ (a) Thomas, J. A. Tuning electronic interactions in mixed valence ruthenium systems incorporating thiacrown ligands. Coord. Chem. Rev. 2013, 257, 1555-1563. (b) Launay, J. P. Electron transfer in molecular binuclear complexes and relation with electron transport through nanojunctions. Coord. Chem. Rev. 2013, 257, 1544-1554. (c) Sakamoto, R.; Katagiri, S.; Maeda, H.; Nishihara, H. Bis(terpyridine) metal complex wires: Excellent long-range electron transfer ability and controllable intrawire redox conduction on silicon electrode. Coord. Chem. Rev. 2013, 257, 1493-1506. (d) Low, P. J. Twists and turns: Studies of the complexes and properties of bimetallic complexes featuring phenylene ethynylene and related bridging ligands. Coord. Chem. Rev. 2013, 257, 1507-1532. (e) Halet, J. F.; Lapinte, C. Charge delocalization vs 
localization in carbon-rich iron mixed-valence complexes: A subtle interplay between the carbon spacer and the (dppe)Cp*Fe organometallic electrophore. Coord. Chem. Rev. 2013, 257, 1584-1613. (f) Kaim, W.; Sarkar, B. Mixed valency of a 5d element: The osmium example. Coord. Chem. Rev. 2013, 257, 1650-1659. (g) Vecchi, A. ; Galloni, P. ; Floris, B. ; Dudkin, S. V. ; Nemykin, V. N. Metallocenes meet porphyrinoids: Consequences of a "fusion". Coord. Chem. Rev 2015, 291, 95-171. (h) Hildebrandt, A.; Lang, H. (Multi)ferrocenyl five-membered heterocycles: Excellent connecting units for electron transfer studies. Organometallics 2013, $32,5623-5625$.

${ }^{3}$ (a) Eisenberg, R. Trigonal prismatic coordination in tris(dithiolene) complexes: Guilty or just non-innocent? Coord. Chem. Rev. 2011, 255, 825-836. (b) Special issue on "Dithiolenes and non-innocent redox-active ligands". Coord. Chem. Rev. 2010, 13-14, 1357-1588.

${ }^{4}$ Kusamoto, T.; Nishihara, H. Zero-, one- and two-dimensional bis(dithiolato)metal complexes with unique physical and chemical properties. Coord. Chem. Rev. 2019, 380, 419-439.

${ }^{5}$ (a) Maj, J. J.; Rae, A. D.; Dahl, L. F. Transition metal-promoted carbon-carbon bond formation by reductive dimerization of carbon disulfide: direct synthesis of the bis(1,2dithiolene-like) tetrathiooxalato $\left(\mathrm{C}_{2} \mathrm{~S}_{4}\right)$ ligand from carbon disulfide by reaction with the dimeric nickel(I) complexes $\mathrm{Ni}_{2}\left(\eta^{5}-\mathrm{C}_{5} \mathrm{R}_{5}\right)_{2}(\mu-\mathrm{CO})_{2}(\mathrm{R}=\mathrm{H}, \mathrm{Me})$. J. Am. Chem. Soc. 1982, 104, 4278-4280. (b) Vicente, R.; Ribas, J.; Cassoux, P.; Valade, L. Synthesis, characterization and properties of highly conducting organometallic polymers derived from the ethylene tetrathiolate anion. Synthetic Metals, 1986, 13, 265-280. (c) Vicente, R.; Ribas, J.; Alvarez, S.; Segui, A.; Solans, X.; Verdaguer, M. Synthesis, X-ray diffraction structure, magnetic properties, and MO analysis of a binuclear ( $\mu$-tetrathiooxalato)copper(II) complex, $\left(\mathrm{AsPh}_{4}\right)_{2}\left[\left(\mathrm{C}_{3} \mathrm{OS}_{4}\right) \mathrm{CuC}_{2} \mathrm{~S}_{4} \mathrm{Cu}\left(\mathrm{C}_{3} \mathrm{OS}_{4}\right)\right]$. Inorg. Chem. 1987, 26, 4004-4009. (d) Pullen, A. E.; Zeltner, S.; Olk, R. M.; Hoyer, E.; Abboud, K. A.; Reynolds, J. R. Extensively Conjugated Dianionic Tetrathiooxalate-Bridged Copper(II) Complexes for Synthetic Metals. Inorg. Chem. 
1996, 35, 4420-4426. (e) Hayashi, M.; Otsubo, K.; Kato, T.; Sugimoto, K.; Fujiwara, A. A compact planar low-energy-gap molecule with a donor-acceptor-donor nature based on a bimetal dithiolene complex. Chem. Commun. 2015, 51, 15796-15799.

6 (a) Köpf, H.; Balz, H. Benzol-1,2,4,5-tetrathiolato-zweikernkomplexe des titanocen-, zirconocen- und hafnocen-systems. J. Organomet. Chem. 1990, 387, 77-81. (b) Balz, H.; Köpf, H.; Pickardt, J. Benzol-1,2,4,5-tetrathiolato-Zweikernkomplexe der 1,1'Bis(trimethylsilyl)metallocene der Titantriade-Synthese und Strukturbestimmung von [( $\eta 5$ $\left.\left.\mathrm{Me}_{3} \mathrm{SiC}_{5} \mathrm{H}_{4}\right)_{2} \mathrm{TiS}_{2}\right]_{2} \mathrm{C}_{6} \mathrm{H}_{2}$ und $\left[\left(\eta 5-\mathrm{Me}_{3} \mathrm{SiC}_{5} \mathrm{H}_{4}\right)_{2} \mathrm{HfS}_{2}\right]_{2} \mathrm{C}_{6} \mathrm{H}_{2}$. J. Organomet. Chem. 1991, 417, 397-406. (c) Arumugam, K.; Shaw, M. C.; Chandrasekaran, P.; Villagrán, D.; Gray, T. G.; Mague, J. T.; Donahue, J. P. Synthesis, structures, and properties of 1,2,4,5benzenetetrathiolate linked group 10 metal complexes. Inorg. Chem. 2009, 48, 10591-10607.

${ }^{7}$ (a) Matsuoka, R.; Sakamoto, R.; Kambe, T.; Takada, K.; Kusamoto, T.; Nishihara, H. Ordered alignment of a one-dimensional $\pi$-conjugated nickel bis(dithiolene) complex polymer produced via interfacial reactions. Chem. Commun. 2014, 50, 8137-8139. (b) Arumugam, K.; Yu, R.; Villagrán, D.; Gray, T. G.; Mague J. T.; Donahue, J. P. A convergent approach to the synthesis of multimetallic dithiolene complexes. Inorg. Chem. 2008, 47, 5570-5572.

${ }^{8}$ (a) McCullough, R. D.; Belot, J. A. Toward new magnetic, electronic, and optical materials: synthesis and characterization of new bimetallic tetrathiafulvalene tetrathiolate building blocks. Chem. Mater. 1994, 6, 1396-1403. (b) McCullough, R. D.; Belot, J. A.; Seth, J.; Rheingold, A. L.; Yap, G. P. A.; Cowan, D. O. Building block ligands for new molecular conductors: homobimetallic tetrathiafulvalene tetrathiolates and metal diselenolenes and ditellurolenes. $J$. Mater. Chem. 1995, 5, 1581-1587. (c) Bellec, N.; Vacher, A.; Barrière, F.; Xu, Z.; Roisnel, T.; Lorcy, D. Interplay between organic-organometallic electrophores within 
bis(cyclopentadienyl)molybdenum dithiolene tetrathiafulvalene complexes. Inorg. Chem. 2015, 54, 5013-5020.

${ }^{9}$ (a) Akiyama, T.; Amino, M.; Saitou, T.; Utsunomiya, K.; Seki, K.-I.; Ikoma, Y.; Kajitani, M.; Sugimaya, T.; Shimizu, K.; Sugimori, A. Structure and electrochemical properties of directly bound dinuclear cobaltadithiolene complexes. Substituent effect on reduction potentials and mixed-valence states. Bull. Chem. Soc. Jpn. 1998, 71, 2351-2358. (b) Keefer, C. E.; Purrington, S. T.; Bereman, R. D.; Boyle, P. D. The first systematic synthesis of heterobimetallic dithiolenebridged complexes. Synthesis and characterization of metal complexes of $4-\left(1^{6}, 2^{6}-\right.$ ethylenedithiolate)-1,3-dithiole-2-one and dimeric metal complexes of 1,2,3,4butadienetetrathiolate. Inorg. Chem. 1999, 38, 5437-5442. (c) Nomura, M.; Fourmigué, M. Dinuclear Cp* cobalt complexes of the 1,2,4,5-benzenetetrathiolate bischelating ligand. Inorg. Chem. 2008, 47, 1301-1312.

${ }^{10}$ Sato, R.; U.S. Patent 20040092775, 2004.

${ }^{11}$ Newell, R.; Ohman, C.; Dubois, M. R. Reactions of sulfido-bridged molybdenum dimers with diynes as a route to multinuclear dithiolene complexes. Organometallics, $\mathbf{2 0 0 5}, 24,4406-$ 4415.

${ }^{12}$ (a) Fourmigué, M. Mixed cyclopentadienyl/dithiolene complexes. Coord. Chem. Rev. 1998, 178-180, 823-864. (b) Fourmigué, M. Paramagnetic Cp/Dithiolene Complexes as Molecular Hinges: Interplay of Metal/Ligand Electronic Delocalization and Solid-State Magnetic Behavior. Acc Chem. Res. 2004, 37, 179-186.

${ }^{13}$ Fourmigué, M.; Domercq, B.; Jourdain, I. V.; Molinié, P.; Guyon, F.; Amaudrut, J. Interplay of structural flexibility and crystal packing in a series of paramagnetic cyclopentadienyl/dithiolene Mo and W complexes : evidence for molecular spin ladders. Chem. Eur. J. 1998, 4, 1714-1723. 
${ }^{14}$ (a) Collison, D.; Garner, C. D.; Joule, J. A. The structure and mode of action of the cofactor of the oxomolybdoenzymes. Chem. Soc. Rev. 1996, 25-32. (b) Hine, F. J.; Taylor, A. J.; Garner, C. D. Dithiolene complexes and the nature of molybdopterin. Coord. Chem. Rev. 2010, 254, 1570-1579.

${ }^{15}$ Davies, E. S.; Beddoes, R. L.; Collison, D.; Dinsmore, A.; Docrat, A.; Joule, J. A.; Wilson, C. R.; Garner, C. D. Synthesis of oxomolybdenum bis(dithiolene) complexes related to the cofactor of the oxomolybdoenzymes. J. Chem. Soc. Dalton Trans. 1997, 3985-3996.

${ }^{16}$ (a) Kaiwar, S. P.; Hsu, J. K.; Vodacek, A.; Yap, G.; Liable-Sands, L. M.; Rheingold, A. L.; Pilato, R. S. Metallo 2,3-disulfidothienoquinoxaline, 2,3-disulfidothienopyridine, and 2sulfido-3-oxidothienoquinoxaline complexes: Synthesis and characterization. Inorg. Chem. 1997, 36, 2406-2412. (b) Hsu, J. K.; Bonangelino, C. J.; Kaiwar, S. P.; Boggs, C. M.; Fettinger, J. C.; Pilato, R. S. Direct Conversion of $\alpha$-Substituted Ketones to Metallo-1,2-enedithiolates. Inorg. Chem. 1996, 35, 4743-4751.

17 Svenstrup, N.; Becher, J. The organic chemistry of 1,3-dithiole-2-thione-4,5-dithiolate (DMIT). Synthesis 1995, 215-235.

18 (a) McGuire, J.; Miras, H. N.; Richards, E.; Sproules, S. Enabling single qubit addressability in a molecular semiconductor comprising gold-supported organic radicals. Chem. Sci. 2019, 10, 1483-1491. (b) Arumugam, K.; Selvachandran, M.; Obanda, A.; Shaw, M. C.; Chandrasekaran, P.; Caston Good, S. L.; Mague, J. T.; Sproules, S.; Donahue, J. P. Redox-active metallodithiolene groups separated by insulating tetraphosphinobenzene spacers. Inorg. Chem. 2018, 57, 4023-4038. (c) Chandrasekaran, P.; Greene, A. F.; Lillich, K.; Capone, S.; Mague, J. T.; DeBeer S.; Donahue, J. P. A structural and spectroscopic investigation of octahedral platinum bis(dithiolene)phosphine complexes: Platinum dithiolene internal redox chemistry induced by phosphine association. Inorg. Chem. 2014, 54, 9192-9205. 
${ }^{19}$ (a) Steimecke, G.; Kirmse, R.; Hoyer, E. Dimercapto-isotrithion-ein neuer, ungesättigter 1,2Dithiolatligand. Z. Chem. 1975, 15, 28-29. (b) Steimecke, G.; Sieler, H.; Kirmse, R.; Hoyer, E. 1,3-dithiol-2-thion-4,5-dithiolat aus schwefelkohlenstoff und alkalimetall. Phosphorus Sulfur 1979, 7, 49 .

${ }^{20}$ Haley, N. F.; Fichtner, M. W. Efficient and general synthesis of 1,3-dithiole-2-thiones. $J$. Org. Chem. 1980, 45, 175-177.

${ }^{21}$ Kutoglu, A.; Köpf, H. Metallocen-dithiolen-chelate. Strukturaufklärung und synthese von benzol-1,2-dithiolato di( $\pi$-cyclopentadienyl)molybdän(IV). J. Organomet. Chem. 1970, 25, $455-460$

${ }^{22}$ Whalley, A. L.; Blake, A. J.; Collison, D.; Davie, E. S.; Disley, H. J.; Helliwell, M.; Mabbs, F. E.; McMaster, J.; Wilson, C.; Garner, C. D. Synthesis, structure and redox properties of bis(cyclopentadienyl)dithiolene complexes of molybdenum and tungsten. Dalton Trans. 2011, 40, $10457-10472$.

${ }^{23}$ D'Alessandro, D. M.; Keene, F. R. A cautionary warning on the use of electrochemical measurements to calculate comproportionation constants for mixed-valence compounds. Dalton Trans., 2004, 3950-3954. (b) Hildebrandt, A.; Miesel, D.; Lang, H. Electrostatic interactions within mixed-valent compounds. Coord. Chem. Rev. 2018, 371, 56-66. (c) Barrière F. Electrostatic modeling of the tuneable potential difference between the two consecutive oxidation steps of dinickel bisfulvalene. Organometallics 2014, 33, 5046-5048. (d) Geiger, W. E.; Barrière, F. Organometallic Electrochemistry Based on Electrolytes Containing WeaklyCoordinating Fluoroarylborate. Anions. Acc. Chem. Res. 2010, 43, 1030-1039. (e) Barrière, F.; Geiger, W. E. Use of Weakly Coordinating Anions to Develop an Integrated Approach to the Tuning of $\Delta \mathrm{E}_{1 / 2}$ Values by Medium Effects. J. Am. Chem. Soc. 2006, 128, 3980-3989.

${ }^{24}$ Hankache, J.; Wenger, O. S. Organic Mixed Valence. Chem. Rev. 2011, 111, 5138-5178. 
${ }^{25}$ Hsu, J. K.; Bonangelino, C. J.; Kaiwar, S. P.; Boggs, C. M.; Fettinger, J. C.; Pilato, R. S. Direct conversion of $\alpha$-substitutes ketones to metallo-1,2-enedithiolates. Inorg. Chem. 1996, $35,4743-4751$.

${ }^{26}$ (a) Bsaibess, T.; Guerro, M.; Le Gal, Y.; Sarraf, D.; Bellec, N.; Fourmigué, M.; Barrière, F.; Dorcet, V.; Guizouarn, T.; Roisnel T.; Lorcy, D. Variable magnetic interactions between S = 1/2 cation radical salts of functionalizable electron-rich dithiolene and diselenolene $\mathrm{Cp}_{2} \mathrm{Mo}$ complexes. Inorg. Chem. 2013, 52, 2162-2173. (b) Le Gal, Y.; Roisnel, T.; Dorcet, V.; Guizouarn, T.; Piekara-Sady L.; Lorcy, D. Chiral electron-rich bis(cyclopentadienyl) dithiolene molybdenum complexes. J. Organomet. Chem. 2015, 794, 323-329.

${ }^{27}$ Sheldrick G.M. SHELXT - Integrated space group and crystal structure determination. Acta Cryst. 2015, A71, 3-8.

${ }^{28}$ Sheldrick G. M. Crystal structure refinement with SHELX. Acta Cryst. 2015, C71, 3-8.

${ }^{29}$ van der Sluis, P.; Spek, A. L. BYPASS: an effective method for the refinement of crystal structures containing disordered solvent regions. Acta Crystallogr., Sect. A. 1990, 46, 194-201.

${ }^{30}$ Spek, A. L. Single-crystal structure validation with the program PLATON. J. Appl. Cryst. 2003, 36, 7-13. 